\title{
Electrophysiological and Pharmacological Evidence for the Role of the Nucleus Accumbens in Cocaine Self-Administration in Freely Moving Rats
}

\author{
Jing-Yu Chang, Steven F. Sawyer, Rong-Sheng Lee, ${ }^{a}$ and Donald J. Woodward \\ Department of Physiology and Pharmacology, Bowman Gray School of Medicine, Wake Forest University, Winston-Salem, \\ North Carolina 27157
}

The goal of this study was to clarify the role of the nucleus accumbens septi (NAS) in the expression of cocaine selfadministration behaviors. Rats were trained in a continuous reinforcement schedule to press a lever to activate a pump that provided an intravenous injection of cocaine. Once the rats were trained, neuronal activity in the NAS was monitored during cocaine self-administration with chronic recording techniques using permanently implanted microwires. In the NAS, $19 \%$ of 181 neurons exhibited either increased or decreased firing rates seconds prior to lever pressing (termed "anticipatory responses"), and $48 \%$ had altered, predominantly decreased, firing rates for a few minutes after lever pressing ("postcocaine responses"). Two-thirds of the neurons with anticipatory responses had postcocaine responses. Neurons with either of these response patterns were localized histologically to both core and shell regions of the NAS, with no statistically significant differences in the proportion of response types in either area. Analysis of videotaped cocaine self-administration behaviors revealed that anticipatory responses were specifically associated either with the animal orienting toward and pressing the lever or only with movements directly related to pressing the lever. Anticipatory-like phasic spike activity was not observed during similar movements unrelated to lever pressing. In some animals, $D_{1}(S C H 23390)$ or $D_{2}$ (pimozide) receptor antagonists were injected systemically prior to or during self-administration sessions to assess the effects of dopamine receptor blockade on anticipatory and postcocaine responses. Each antagonist, given separately, often produced extinction of lever pressing. Both antagonists blocked the postcocaine inhibitory response of neurons that had anticipatory responses. Neither antagonist modified anticipatory unit responses, nor did they affect postcocaine inhibitory responses in neurons that did not exhibit anticipatory responses. Taken together, these results suggest that the role of the NAS in cocaine self-administration may consist of two

\footnotetext{
Received Feb. 26, 1993; revised May 19, 1993; accepted Aug. 12, 1993.

We appreciate the critical appraisal of the manuscript by Drs. Roy Wise and Joseph Paris. This work was supported by DA 2338, NIAAA 3901, and AFOSR 90-0146 to D.J.W.

Correspondence should be addressed to J.-Y. Chang, Department of Physiology and Pharmacology, Bowman Gray School of Medicine, Wake Forest University, Medical Center Boulevard, Winston-Salem, NC 27157.

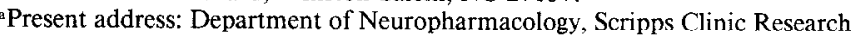
Institute, La Jolla, CA 92037.

Copyright C 1994 Society for Neuroscience $0270-6474 / 94 / 141224-21 \$ 05.00 / 0$
}

different mechanisms: (1) An initiation or trigger mechanism, as represented by the anticipatory neuronal responses, in which the NAS participates in triggering or mediating the goal-directed behaviors (e.g., lever pressing) that lead to the acquisition of the reinforcing agent (e.g., cocaine). Considering that anticipatory responses were not altered by dopamine receptor antagonists, this initiation mechanism may not be mediated by dopamine transmission but rather may derive from signals carried by other afferents to the NAS. (2) The NAS may play a critical role in the neural circuitry that underlies the rewarding aspects of cocaine self-administration, as represented by the postcocaine responses. This mechanism may be under the influence of dopaminergic neurotransmission, which is enhanced by cocaine, possibly within the NAS.

[Key words: cocaine, dopamine, self-administration, nucleus accumbens, electrophysiology, behavior]

The goal of this study was to determine the role of the nucleus accumbens septi (NAS) in mediating cocaine self-administration behaviors. The NAS, a substantial component of the "ventral striatum" (Heimer and Wilson, 1975), is a pivotal structure connecting limbic and basal ganglia systems. The NAS in rats receives abundant afferent connections from the prelimbic cortex (Groenewegen et al., 1982; Phillipson and Griffiths, 1985; Christie et al., 1987; Brog et al., 1991), hippocampal formation (Kelley and Domesick, 1982; Groenewegen et al., 1987), amygdala (Kelley et al., 1982; Robinson and Beart, 1988; McDonald, 1991), midline thalamic nuclei (Su and Bentivoglio, 1990), and ventral tegmental area (VTA) (Nauta et al., 1978; Swanson, 1982; Oades and Halliday, 1987). In turn, the NAS projects to the ventral pallidus (Zahm and Heimer, 1990; Heimer et al., 1991), pedunculopontine nucleus, hypothalamus, substantia nigra, and VTA (Nauta et al., 1978; Domesick, 1981; Mogenson et al., 1983; Groenewegen and Russchen, 1984; Heimer at al., 1991). Clarification of neural mechanisms of the execution of cocaine self-administration behavior (and other goal-directed behaviors) will require study of neural activity in all of these connected regions.

In accordance with this anatomical profile, a number of electrophysiological studies performed primarily in anesthetized animals have revealed complex interactions between different inputs on neuronal activity within the NAS. Stimulation of the cerebral cortex, hippocampal formation, amygdala, or parafascicular nucleus evokes an excitatory response in NAS neurons, 
mediated in part by NMDA and non-NMDA glutamate receptors (Uchimura et al., 1989; Pennartz et al., 1991). These excitatory responses are modulated by catecholamines, as indicated by the effects of stimulation of VTA or locus coeruleus, the major source of dopaminergic and noradrenergic inputs, respectively, to the NAS (Akaike et al., 1984; Yang and Mogenson, 1984; DeFrance et al., 1985; Unemoto et al., 1985; Yim and Mogenson, 1988). Microiontophoretic application of dopamine receptor agonists inhibits extracellularly recorded spike activity in the NAS of anesthetized animals, an effect that appears to be mediated by both $D_{1}$ and $D_{2}$ dopamine receptors (White and Wang, 1986; White et al., 1987). Moreover, it has been suggested that the synergistic action of these two dopamine receptor subtypes may be necessary for the full expression of dopamine's effects (White, 1987). Activation of "inhibitory" VTA dopaminergic inputs to the NAS has been thought to disinhibit ventral pallidal neurons indirectly from GABAergic input originating in the NAS. This results in an increase in firing rate of ventral pallidal neurons and enhancement of output circuits involved in the expression of locomotor activity (Yim and Mogenson, 1983; Yang and Mogenson, 1987, 1989). Cocaine is likely to affect these circuits, since it can enhance dopaminergic neurotransmission in the NAS due to its ability to block uptake of dopamine by dopaminergic axons (Heikkila et al., 1975; Kennedy and Hanbauer, 1983; Ritz et al., 1987). However, this effect on uptake also suppresses spike activity of the dopaminergic neurons in the VTA in a dose-dependent manner (Einhorn et al., 1988), which would be expected to decrease impulse-dependent release of dopamine in terminal fields of VTA neurons. Thus, it is not clear which effect of cocaine on synaptic levels of dopamine will prevail in the NAS in a behavioral context of an animal self-administering cocaine.

On anatomical and physiological grounds, the NAS has been hypothesized to exert a "filtering" or "gating" function on its limbic afferents, and to initiate or modulate goal-directed behavior (Mogenson, 1987) such as feeding, drinking, sexual activity, and reward seeking (Heffner et al., 1980; Blackburn et al., 1986; Robertson et al., 1991). Based on findings from a number of studies during the past decade, a consensus has developed that the NAS is a critical brain nucleus in the selfadministration of dopaminergic psychomotor drugs, such as cocaine (Koob and Bloom, 1988; Wise, 1989). In support of this concept, lesions of neuronal cell bodies or dopaminergic terminals in the NAS greatly reduce cocaine self-administration in rats (Roberts et al., 1977, 1980; Pettit et al., 1984; Zito et al., 1985), indicating a prominent role for neurons and dopaminergic neurotransmission in the NAS in the expression of such behaviors. Furthermore, in animals trained to press a lever to self-administer cocaine or amphetamine, systemic injection of $D_{1}$ or $D_{2}$ dopamine receptor antagonists induces an extinction response, in which the animal initially increases the rates of selfadministration and eventually ceases self-administration. Extinction is attributed to blockade of dopamine-mediated rewarding stimuli (Yokel and Wise, 1975; de Wit and Wise, 1977; Ettenberg et al., 1982; Woolverton, 1986; Koob et al., 1987; Britton, et al., 1991). Likewise, application of dopamine receptor antagonists directly into the NAS potently extinguishes both cocaine self-administration (Phillips et al., 1983; Maldonado et al., 1991) and self-stimulation of brain areas (e.g., VTA or medial forebrain bundle) that, when stimulated, produce increased release of dopamine in the NAS (Mogensen et al., 1979; Kurumiya and Nakajima, 1988; Stellar and Corbett, 1989). While these findings provide evidence that the NAS is critical to the rewarding effects of cocaine and medial forebrain bundle stimulation, it is not clear what neural information arriving in the NAS is modulated and transmitted to the brainstem and thalamocortical systems.

A useful experimental approach for clarifying the critical role of the NAS in rewarding events and goal-directed behavior is the use of chronic electrophysiological recording methods in freely moving animals. Although a number of electrophysiological studies of neuronal activity in the NAS in behaving animals have been carried out (Rolls, 1984; Fukuzako et al., 1988; Peoples and West, 1990; Apicella et al., 1991; Schultz et al., 1992; Wolske et al., 1993), little is yet known about the specific patterns of neuronal activity in these brain regions during the motor acts leading to self-administration of drugs of abuse. The aim of the work presented here was to conduct an investigation into the neural mechanisms of drug-seeking behavior by monitoring the spike activity of NAS neurons in rats as they self-administered cocaine.

Preliminary aspects of this study have been reported in abstract form (Chang et al., 1990, 1991).

\section{Materials and Methods}

Animals and surgery. Twenty-eight adult male Long-Evans rats weighing 250-300 gm were used in these experiments. Animals were housed in a reverse dark/light cycle (lights off 7:00 to 19:00) and experiments were performed during their active (dark) period. In preparation for surgery, rats were anesthetized with pentobarbital $(50 \mathrm{mg} / \mathrm{kg}$, i.p.). Two splayed bundles of eight stainless steel Teflon-insulated microwires, soldered onto connecting pins on a headstage, were stereotaxically lowered bilaterally into the NAS (eight wires in each NAS). The diameter of individual microwires was $50 \mu \mathrm{m}$, and the diameter of the splayed bundle was about $500 \mu \mathrm{m}$. Coordinates for the NAS were obtained from the atlas of Paxinos and Watson (1986): $1.4 \mathrm{~mm}$ lateral to midline, 1.8 $2.0 \mathrm{~mm}$ anterior to bregma, $6.5-6.8 \mathrm{~mm}$ ventral to the dorsal surface of the brain. Ground wires were positioned $2-3 \mathrm{~mm}$ ventral to the cortical surface. The headstage was secured on to the cranium with dental cement using skull screws as anchors. About 1 week after microwire implantation, Silastic tubing ( $26 \mathrm{~mm}$ long, $0.3 \mathrm{~mm}$ i.d. cannula tubing, connected to a $90 \mathrm{~mm}$ long, $0.6 \mathrm{~mm}$ i.d. inlet tubing) was inserted under sterile conditions in the right jugular vein for subsequent intravenous drug infusion. The infusion tubing was glued to a Silastic implant sheeting, which was sutured to subdermal connective tissue. The exposed end of the tubing, which was blocked except when connected to an injection syringe, emanated from the dorsal aspect of the neck. Animals received ampicillin $(60,000 \mathrm{U}$, i.m.) after surgery, and were housed individually after surgery. Animals were treated in accordance with the U.S. Public Health Service Guide for the Care and Use of Laboratory Animals.

Apparatus and behavioral training. Five to seven days after surgery, rats were placed in separate rectangular operant conditioning cages, each of which was enclosed in a sound-attenuating chamber. Cage dimensions were $20 \mathrm{~cm} \times 23 \mathrm{~cm}$, and $20 \mathrm{~cm}$ in height. A lever was mounted on one wall, $8 \mathrm{~cm}$ above the cage floor. Daily experimental sessions typically began about $2 \mathrm{hr}$ into the animal's dark cycle and lasted 2-3 hr. Rats were initially trained to press the lever for a water reward using a continuous reinforcement schedule; later, cocaine was substituted for water. For cocaine administration, the indwelling jugular cannula was connected to an infusion pump via a plastic tube. Pressing the lever activated the pump for $4 \mathrm{sec}$ (with a $0.5 \mathrm{sec}$ delay), thereby infusing approximately $1 \mathrm{mg} / \mathrm{kg}$ of cocaine $(0.33 \mathrm{mg}$ in $0.1 \mathrm{ml}$ of lactated Ringer's solution) into the jugular vein. With this dose, lever pressing occurred at about 5 min intervals. A cue to the animal that cocaine infusion was imminent was the audible closing of the lever switch when pressed. A red light-emitting diode (LED) was mounted in the chamber $3 \mathrm{~mm}$ above the lever. This LED was turned on by lever pressing, and was used by the experimenters to confirm the temporal accuracy of video analysis (see below). There was no evidence that rats attended to this LED as a cue during cocaine self-administration protocols. Rats usually learned the self-administration paradigm within about $7 \mathrm{~d}$. Certain an- 


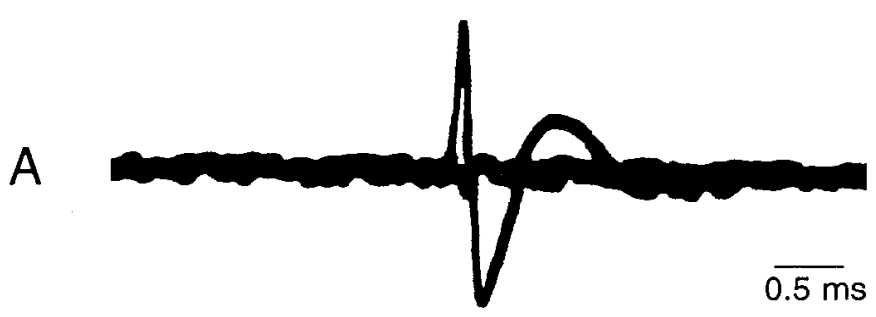

B

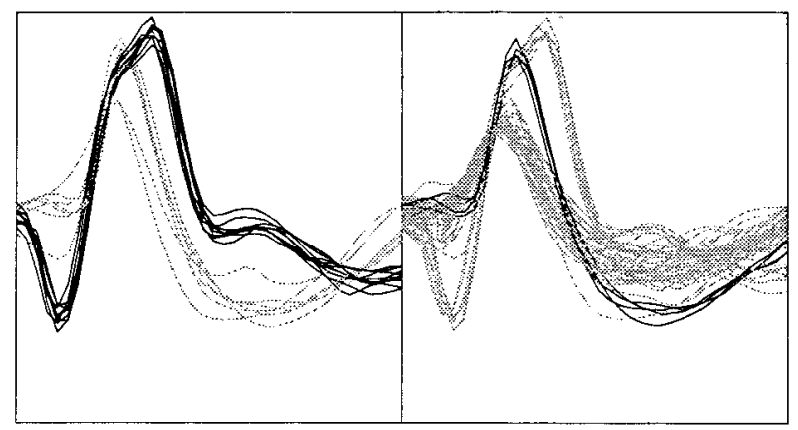

$\overline{0.2 \mathrm{~ms}}$

Figure 1. Extracellular recordings of neuronal activity from the NAS of a rat during self-administration trials using chronically implanted microwires. $A$, Photographic image of oscilloscope traces of an extracellularly recorded action potential. $B$, Two NAS neurons whose spike activity was recorded from the same microwire. Spike sorting was performed with a computer-controlled window discriminator. In each pan$\mathrm{el}$, the isolated (spike-sorted) unit is shown as a solid line; other nonisolated waveforms are shown as hroken lines. Different neurons in $A$ and $B$. Positive polarity is up.

imals were also tested for the effects of gross body movement in a computer-controlled treadmill that turned on and off in $30 \mathrm{sec}$ intervals.

Electrophysiological recording. When the animals were trained to selfadminister cocaine, neuronal activity was recorded from implanted microwires during experimental sessions by securing a detachable headset (containing 16 field effect transistors, one for each microwire) to the headstage cemented on the animal's head. Lightweight cabling connected the headset to a commutator and electronics (described below), permitting the animals unrestricted movement in the operant chamber. Neuroelectric signals were passed in to separate amplifying, filtering $(0.5$ and $5 \mathrm{kHz}, 3 \mathrm{~dB}$ cutoffs), and window discriminator channels. In later stages of the study, programmable spike amplification, filtering, and spike sorting was performed with software and electronics obtained from Spectrum Scientific (Dallas, TX). The in vitro impedance of microwires was $100-200 \mathrm{k} \Omega$ at $1 \mathrm{kHz}$; in vivo values were estimated to be similar. As many as five NAS neurons were monitored concurrently. When spike activity was recorded from the same microwire across different self-administration sessions, the following criteria were used to infer that the same neuron was recorded in the different sessions: (1) constancy of the shape and polarity of the extracellular spike waveform, and (2) similarities in firing rate and pattern (e.g., interspike interval and autocorrelation histograms). As a caveat, it should be mentioned that such inferences are subject to dispute and were not critical to most of the conclusions of this study. However, there were many instances in which the criteria were met and the units appeared to be the same across consecutive sessions. This was particularly unambiguous in cases of larger-amplitude waveforms (signal-to-background ratio $>7$ ).

Spike activity, lever pressing, pump activation, and the LED were monitored or controlled with data acquisition software operating on a general purpose minicomputer with a time resolution of $1 \mathrm{msec}$. Neuronal spike activity was collected on a daily basis for up to 4 weeks.

Implanted microwires for chronic recording of neuronal activity. The use of implanted microwires for recording extracellular neural activity has a number of methodological features that distinguish it from the more conventional use of a chronic microdrive apparatus. (1) Instead of lowering a single recording probe (microelectrode) into the brain, bundles of microwires can be implanted in the NAS, thereby permitting concurrent monitoring of many neurons from multiple probes. The larger number of recording probes compensates for the relatively low number of neurons that can be recorded from each permanently positioned microwire. (2) Implanted microwires afford much more stable recording conditions. Recordings from the same neuron can often be accomplished over many days, presumably due to the stability of the microenvironment surrounding the implanted microwires. (3) Adjacent microwires can be used for differential recording, providing superior common mode rejection of movement artifacts. (4) Anatomically precise localization of recording sites can be accomplished by passing current through the microwires at the end of experimentation and then reconstructing the sites histologically.

Video analysis of behavior. The animal's behavior during self-administration sessions was recorded on videotape with the experimental time superimposed on the display for off-line analysis. Accuracy of the experimental time on the video display was confirmed by comparing time points of lever pressing in the video display (i.e., onset of LED turning on) with time stamps of lever switch closing as recorded by the computer. Frame by frame analysis of behavior, at 30 frames/sec, provided 33 msec temporal resolution. Interframe times could be interpolated into thirds, permitting approximately $11 \mathrm{msec}$ resolution. Evaluation of behavioral time epochs with respect to concurrent spike activity was performed off line with special-purpose computer software written by Dr. John Chapin (Hahnemann University).

Histology. At the conclusion of the final experimental session, 10-20 sec of $10-20 \mu \mathrm{A}$ positive current was passed through selected microwires to deposit iron ions. The marking current was passed through no more than three microwires in a bundle of eight microwires, since it was not possible to distinguish more than three sites using different current parameters. Since it was often the case that more than three microwires in a bundle of eight yielded isolated single units, it was not possible to reconstruct every recording site. Microwires from which "anticipatory responses" (see Results) were recorded were preferentially selected for marking. The animals were then killed and perfused with formalin. Coronal sections through the NAS were mounted on slides. Incubation of the mounted sections in a solution of $5 \%$ potassium ferricyanide and $10 \% \mathrm{HCl}$ revealed iron deposits (recording sites) in the form of blue dots (Green, 1958). If marked recording sites were localized to the NAS, it was assumed that unmarked microwires had also been positioned in the NAS since the dispersion diameter of the implanted microwire bundles was no more than $0.5 \mathrm{~mm}$ (as verified in situ with $\mathrm{x}$-rays).

Drugs. Cocaine hydrochloride $(3.33 \mathrm{mg} / \mathrm{ml}$; Sigma, St. Louis, MO) and heparin $(10 \mathrm{U} / \mathrm{ml})$ were dissolved in Ringer's solution and filter sterilized $(0.22 \mu \mathrm{m})$. Pimozide and SCH 23390 were obtained from Research Biochemicals Inc., Natick, MA. Pimozide $(0.25 \mathrm{mg} / \mathrm{ml})$ was dissolved in $2.5 \%$ acetic acid in physiological saline before injection. SCH 23390 was dissolved in physiological saline.

Statistics. Pair-wise comparisons of means were evaluated with a twotailed Student's $t$ test. Analysis of variance (ANOVA) was used when evaluating more than two groups, with the Tukey highest significant difference (HSD) test used for specific comparisons when indicated by ANOVA. Independence of probability distribution was assessed with the $\chi^{2}$ test using the Yates correction for continuity (Zar, 1984). Statistical analyses were performed with a commercially available software program (SYSTAT, Inc.). Data are presented as mean \pm SEM.

\section{Results}

Neuronal activity in the nucleus accumbens during cocaine self-administration

Chronic recording across multiple self-administration sessions. All neurons reported in this study were localized histologically to the NAS. A total of 129 electrophysiological recording sessions were performed during lever pressing for cocaine, ranging from 2 to 23 sessions per rat. In a given session, one to five isolated neurons were recorded. Each isolated neuron recorded during a session was defined as a "neuron-session." Spike sorting allowed the occasional isolation of two or three units from a single microwire. 
Table 1. Summary of firing rates of NAS neurons during self-administration of cocaine

\begin{tabular}{|c|c|c|c|c|c|c|}
\hline \multirow[b]{2}{*}{ Type of response } & \multirow{2}{*}{$\begin{array}{l}\text { Control interval } \\
\text { firing rate }\end{array}$} & \multicolumn{2}{|c|}{ Pre-lever press interval } & \multicolumn{2}{|c|}{ Post-lever press interval } & \multirow[b]{2}{*}{$n$} \\
\hline & & Firing rate & Change & Firing rate & Change & \\
\hline \multicolumn{7}{|l|}{$\begin{array}{l}\text { No anticipatory or } \\
\text { postcocaine }\end{array}$} \\
\hline responses & $4.43 \pm 0.42$ & $4.51 \pm 0.42$ & $+10 \pm 4 \%$ & $4.25 \pm 0.41$ & $-1 \pm 1$ & 82 \\
\hline $\begin{array}{l}\text { Excitatory- } \\
\text { anticipatory (all } \\
\text { cases) }\end{array}$ & $3.19 \pm 0.57$ & $8.03 \pm 1.52$ & $+181 \pm 32 \%$ & $2.89 \pm 0.60$ & $-13 \pm 9 \%$ & 18 \\
\hline $\begin{array}{l}\text { Inhibitory- } \\
\text { anticipatory (all } \\
\text { cases) }\end{array}$ & $3.22 \pm 0.54$ & $1.43 \pm 0.39$ & $-62 \pm 5 \%$ & $3.41 \pm 0.66$ & $+7 \pm 12 \%$ & 17 \\
\hline $\begin{array}{l}\text { Postcocaine } \\
\text { excitation (not } \\
\text { anticipatory) }\end{array}$ & $3.79 \pm 0.95$ & $3.28 \pm 0.79$ & $-6 \pm 8 \%$ & $5.34 \pm 1.21$ & $+52 \pm 10 \%$ & 14 \\
\hline $\begin{array}{l}\text { Postcocaine } \\
\text { inhibition (not } \\
\text { anticipatory) } \\
\end{array}$ & $3.45 \pm 0.50$ & $3.34 \pm 0.48$ & $-2 \pm 6 \%$ & $2.23 \pm 0.38$ & $-40 \pm 2 \%$ & 50 \\
\hline $\begin{array}{l}\text { Postcocaine } \\
\text { excitation (all } \\
\text { cases) }\end{array}$ & $4.03 \pm 0.82$ & $4.26 \pm 1.06$ & $+16 \pm 25$ & $5.37 \pm 0.90$ & $+49 \pm 7$ & 24 \\
\hline $\begin{array}{l}\text { Postcocaine } \\
\text { inhibition (all } \\
\text { cases) }\end{array}$ & $3.21 \pm 0.41$ & $3.50 \pm 0.42$ & $19 \pm 12$ & $2.02 \pm 0.31$ & $-42 \pm 2$ & 63 \\
\hline
\end{tabular}

A total of 181 neurons examined in the NAS, and classified into three broad categories based on response profiles: no response (no change in firing rate during anticipatory

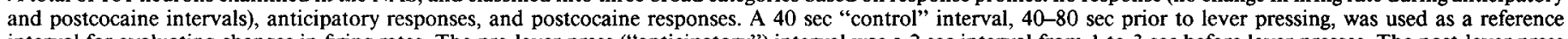

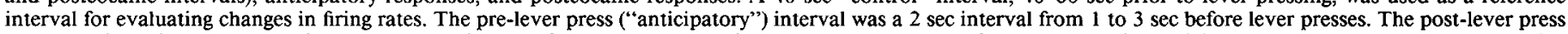

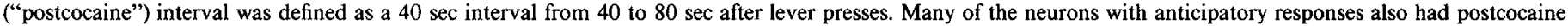

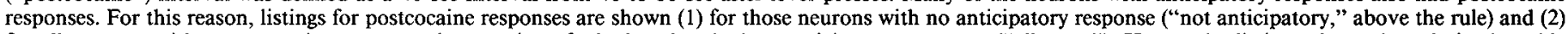

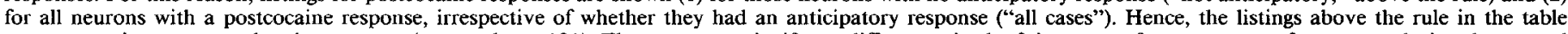

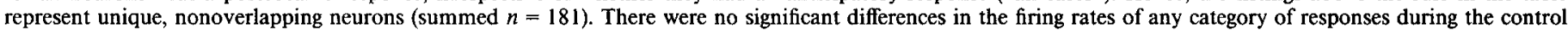
intervals (ANOVA Tukey HSD test, $p>0.05$ ). $n=$ number of neurons.

For all animals, a total of 398 neuron-sessions were recorded in the NAS from 101 microwires. In cases in which isolated units were obtained from the same microwire across multiple sessions, it was probable that the activity of the same neuron was monitored across at least some of these sessions. A maximum of 398 ncurons wcre rccordcd, if different neurons were always recorded from microwires in different sessions. A minimum of 110 neurons were recorded, if the same neurons were always recorded by microwires across multiple sessions (taking into account instances when multiple isolated units were recorded from single microwires). However, using our criteria (see Materials and Methods) to determine whether the same neuron was recorded across experimental sessions, it was inferentially estimated that a total of 181 different neurons were monitored in this study. Figure 1 shows representative extracellularly recorded waveforms from neurons located in the NAS.

Behavioral correlates. Rats that were trained to press the lever and self-administer cocaine characteristically spent the majority of their time during a self-dosing session performing stereotyped behaviors (e.g., head bobbing, sniffing, rearing) on a side of the chamber away from the lever. Typically, the animal broke from stereotypy at about $5 \mathrm{~min}$ intervals and oriented toward and approached the lever. Usually within 2-20 sec after breaking from stereotypy, the animal pressed the lever, thereby activating the pump that delivered cocaine intravenously. Within seconds of successfully pressing the lever, rats usually turned and moved away from the lever and resumed stereotyped behaviors.

Firing rates of NAS neurons were evaluated during three be- havioral epochs: (1) a fixed interval prior to lever pressing within the intertrial phase between lever presses, when the animal was typically engaged in stereotypy; (2) a pre-lever pressing interval during which the animal oriented to and pressed the lever for drug infusion; and (3) a fixed interval following lever pressing. Calculation of changes in spike activity in these three epochs involved selection of behaviorally relevant intervals. For the intertrial phase, spike activity was averaged during a $40 \mathrm{sec}$ interval between 40 and $80 \mathrm{sec}$ prior to lever pressing, since this best represented baseline spike activity during a "control" interval (although some comparisons used a $3 \mathrm{sec}$ control interval, as mentioned below). Pre-lever pressing activity was evaluated during a $2 \mathrm{sec}$ interval, between 1 and $3 \mathrm{sec}$ prior to lever pressing, as this interval was found empirically to encompass the time of maximal alterations in spike activity prior to lever pressing. Activity during postcocaine intervals was examined during a $40 \mathrm{sec}$ interval beginning $40 \mathrm{sec}$ after lever pressing.

The mean firing rate for all recorded NAS neurons during the $40 \mathrm{sec}$ control period was $3.83 \pm 0.26 \mathrm{spikes} / \mathrm{sec}$ (range $=0.08-$ 19.49 ; median $=2.70 \mathrm{~Hz} ; n=181$ neurons). Based on alterations in firing rate during the pre- and post-lever pressing phases, neurons in the NAS were classified into threc broad catcgorics (Table 1): (1) no change: neurons with no significant alteration in firing rate during the pre- or post-lever pressing intervals, defined as less than a $20 \%$ change from baseline and no statistically significant difference at the $p>0.01$ level $(t$ test, vs 40 sec control interval; $+10 \pm 4 \%$ change for pre-lever pressing phase and $-1 \pm 1 \%$ change for post-lever pressing phase; 82 

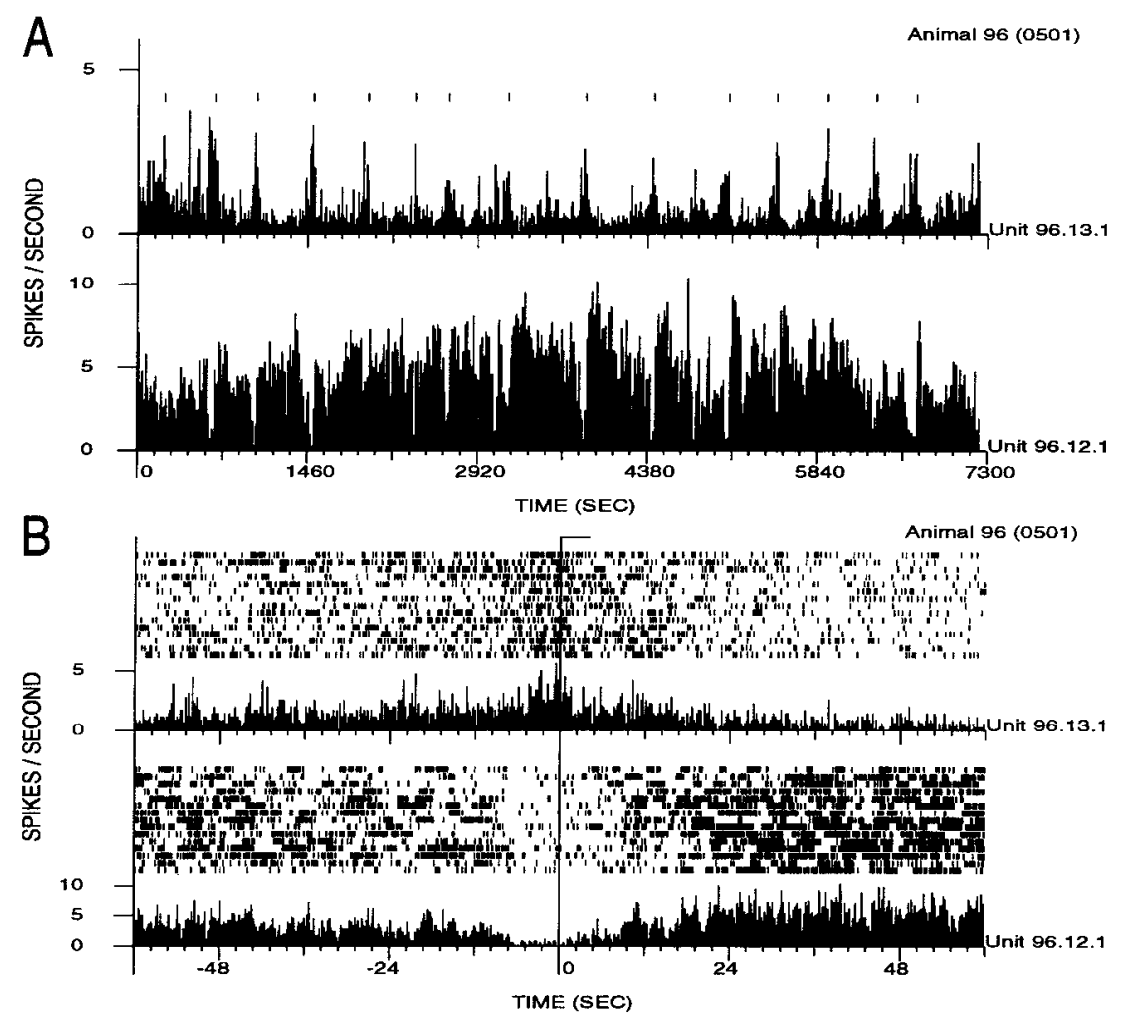

Figure 2. Spike activity of two NAS neurons recorded concurrently from the same microwire bundle during self-administration of cocaine. $A$, Stripcharts of spike activity of the two neurons during a 7300 -sec-duration session. The short vertical lines above the stripcharts represent lever presses that activated the pump for intravenous cocaine infusion. The animal pressed the lever about every 7-8 min. Note the reciprocal nature of altered spike activity: neuron 96.13 .1 (top stripchart) had increased, whereas neuron 96.12 .1 (bottom stripchart) had decreased, spike activity centered around lever pressing. B, Raster plots (top in each pair of graphs) and perievent histograms (bottom in each pair) for the data shown in $A$. In this and other figures, each vertical tick mark in a raster plot represents an action potential, and each row of vertical tick marks shows spike activity during a trial within the session; the long vertical line (at time $-0.5 \mathrm{sec}$ ) in raster plots and perievent histograms indicates the closing of the lever press switch due to animal pressing the lever (except Fig. 11); the horizontal line above the graphs (from time 0 to 4 sec) indicates the activation of the pump that provided intravenous administration of cocaine (except Fig. 11); labeling of the animal number from which the data werc obtaincd above cach graph includes a number in parentheses, which refers to the date of the experiment in a "month day" format; and labeling of neurons (Unit) to right of graphs refers to "animal number.microwire number.unit number." Neuron 96.13 .1 (top raster and histogram pair) had a pronounced increase in firing rate beginning about $5 \mathrm{sec}$ prior to lever pressing and a return to baseline rates about 3 sec after lever pressing, that is, an excitatory-anticipatory response. In contrast, neuron 96.12.1 (bottom) had decreased spike activity preceding and following lever pressing, that is, an inhibitory-anticipatory response. Phasic activity for both of these responses was temporally coincident. Note that the responses for these neurons persisted for a few seconds after the lever press; other NAS neurons with anticipatory responses exhibited prompt termination of phasic activity after lever pressing (Figs. 4-9).

neurons in 23 rats); (2) anticipatory responses: neurons with an increase $(+181 \pm 32 \% ; 18$ neurons in 10 rats) or decrease $(-62$ $\pm 5 \% ; 17$ neurons in 10 rats) in firing rate during the pre-lever pressing interval, referred to as "excitatory-anticipatory" and "inhibitory-anticipatory" responses, respectively (the term "anticipatory" is operationally defined as a change in firing rates observed prior to lever pressing); (3) postcocaine responses: neurons with a protracted increase $(+49 \pm 7 \%$ from 24 neurons in 9 rats) or decrease $(-42 \pm 2 \%$ from 63 neurons in 19 rats) in firing rate during the post-lever pressing interval, referred to as "postcocaine excitation" and "postcocaine inhibition" responses, respectively. Most of the neurons with anticipatory responses also exhibited postcocaine inhibitory responses. Of the 18 excitatory-anticipatory neurons, nine had a postcocaine inhibition, threc had a postcocaine excitatory response, and six had no change. In contrast, for inhibitory-anticipatory neurons, postcocaine excitatory responses were more common (7 of 17) than postcocaine inhibitory responses (4 of 17).

By definition, NAS neurons with excitatory-anticipatory $(10 \%$ of population) and inhibitory-anticipatory ( $9 \%$ of population) responses were characterized by an increase or decrease in firing rate $1-3$ sec prior to lever pressing. However, the interval over which firing rates for anticipatory neurons were altered proved to be contingent upon the duration of lever pressing-related behaviors. Figure 2 illustrates representative anticipatory responses of two concurrently recorded neurons in the NAS during a cocaine self-administration session. Note that these two concurrently recorded neurons had reciprocal anticipatory responses, as one neuron had an excitatory-anticipatory response and the other an inhibitory-anticipatory response.

An example of a postcocaine inhibitory response is presented in Figure 3, in which a pronounced postcocaine inhibition gradually decayed over a few minutes. This neuron did not have an anticipatory response. The animal consistently self-administered cocaine whenever the firing rate of this neuron attained baseline levels, demonstrating a relation between the duration of postcocaine inhibition by an NAS neuron and the intertrial interval of self-administration cocaine. For all neurons with postcocaine inhibitory responses, the duration of the inhibition was $233 \pm 19$ sec.

Video analysis: relation of self-administration behaviors to neuronal activity in the NAS. For selected sessions, the relation 

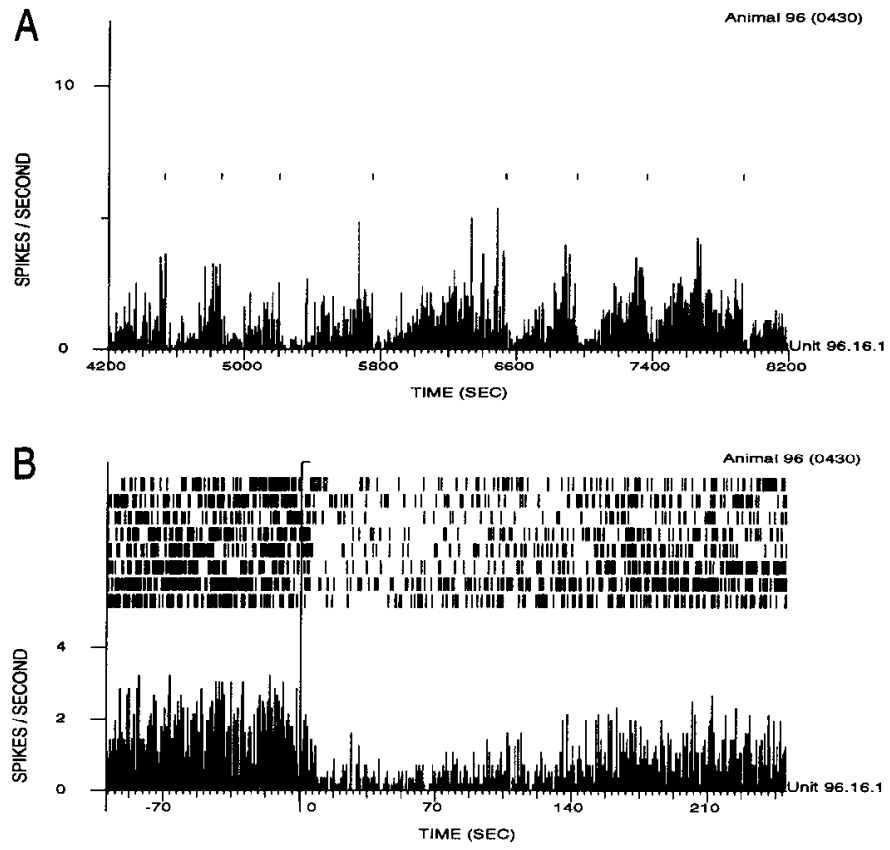

Figure 3. Stripchart $(A)$, raster plot and perievent histogram $(B)$ of a postcocaine inhibitory response in the absence of an anticipatory response by an NAS neuron. The decrease in spike activity begins about $5 \mathrm{sec}$ after cocaine infusion. The short vertical lines above the stripcharts represent lever presses that activated the pump for intravenous cocaine infusion. Note that the inhibition of spike activity gradually decayed following cocaine administration over the course of about 5 min. Upon reinstatement of baseline firing rates, the animal reliably self-administered cocaine.

between the anticipatory neuronal responses in the NAS and lever pressing for cocaine self-administration was evaluated off line with frame-by-frame analysis of videotaped lever-pressing behaviors for cocaine self-administration. Bchaviors relatcd to lever pressing were fractionated into the following categories, which typically occurred in a temporal sequence (1-6): (1) turning to lever, whose onset was defined as when the rat interrupted stereotyped behaviors to orient and move toward the side of the chamber where the lever was located; (2) facing lever, in which the animal, now having approached the lever, often remained fixed in place for a short period of time; this was usually followed by (3) raising head to lever, at which time the animal moved its head in the direction of the lever, with its forelimbs still on the floor; at this time, a (4) rearing to lever interval began when a forelimb was lifted off the floor - this interval terminated when a forelimb made contact with the lever; (5) lever to floor consisted of the animal, already touching the lever, pressing the lever, and removing its forelimb(s) from the lever and placing them on the floor, thereby completing behaviors specific to lever pressing; at this point, the animals typically were soon (6) turning away from lever in the direction of another side of the cage. Successful lever pressing was indicated to the animal by an

Figure 4. Time course of altered spike activity for an excitatory, lever press-related anticipatory response by an NAS neuron, based on video analysis of lever-pressing behaviors during nine trials of a cocaine selfadministration session. Data under dashed lines in $B$ are summarized graphically in $A$. $A$, Bar graph showing firing rates during different fractionated behaviors, and the durations of the behaviors, that were related to orienting toward and pressing of the lever. Firing rates and durations
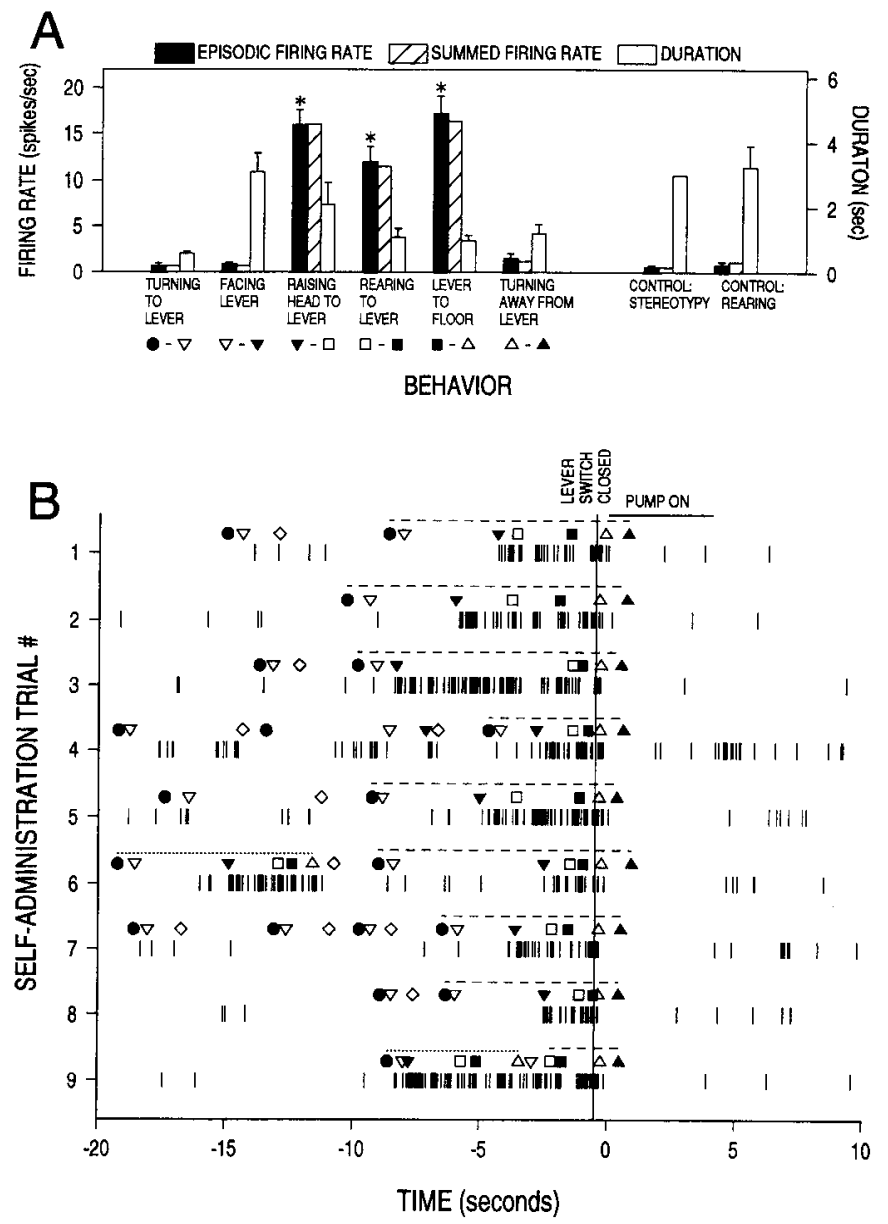

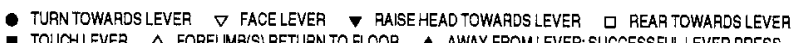
- TOUCHLEVER $\triangle$ FORELIME(S) RETURN TO FLOOR A AWAY FROM LEVER: SUCCESSFUL LEVER PRESS

of control (stereotypy, rearing) intervals, which took place when the animal was away from and not attending to the lever, are also presented. Refer to text for a more complete description of the fractionated behaviors. Firing rates for the occurrence of each behavior interval for each trial are displayed as solid bars (i.e., episodic firing rates; data are shown as mean \pm SEM). Summed firing rates were calculated by summing spike counts and durations for each respective behavior across all trails, and are displayed as hatched bars. The duration of each episodic behavior interval is displayed as open bars. Firing rates for control stereotypy intervals were calculated during $3 \mathrm{sec}$ intervals, $97-100 \mathrm{sec}$ prior to lever pressing. The pairs of symbols under each set of bar graphs refer to the corresponding behavioral intervals in $B$ that were used for calculating firing rates and behavior in $A$; only behaviors that led to successful lever pressing (dashed lines in $B$ ) were used for generating data summarized in $A$. Note that increased firing rates were restricted to lever pressing-related movements (raising head to lever, rearing to lever, lever to floor), and did not occur when the animal oriented toward and approached the lever (turning to lever, facing lever). Lever pressing occurred during the "lever to floor" interval as labeled in $A$. The lower, baseline firing rates were reinstated in less than $0.5 \mathrm{sec}$ after lever pressing, as the animal turned away from the lever. Asterisks above bar graphs indicate fractionated behaviors with statistically significant differences in firing rates when compared to control stereotypy firing rates $(p<$ 0.05 , Tukey HSD test). $B$, Raster plot of the nine self-administration trials used to calculate data summarized in $A$. Each numbered row on the $y$-axis represents a lever press trial; symbols above each row represent the onset of the specified behavior. In some instances, the lever was not pressed with sufficient force to close the switch (dotted lines in trials 6 and 9), necessitating a second press for cocaine administration. Examination of this raster with reference to behavior symbols reveals that increased levels of spike activity were restricted to behaviors directly related to lever pressing. 

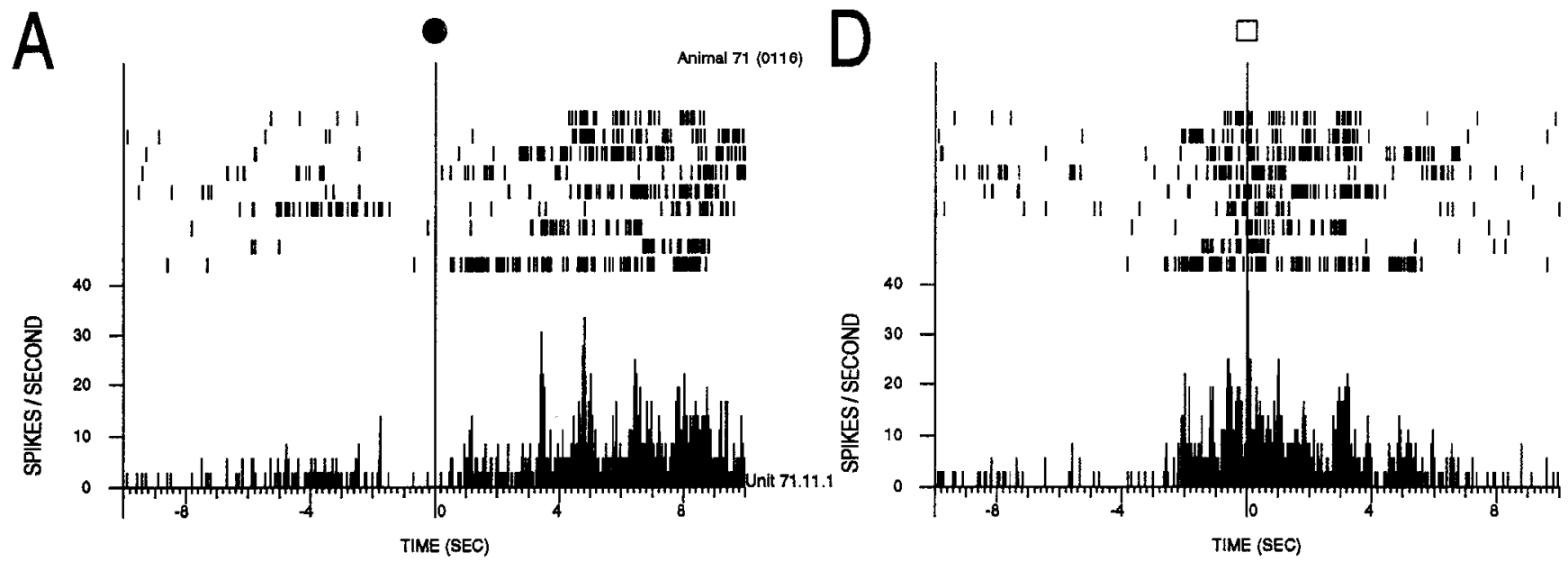

FACE LEVER

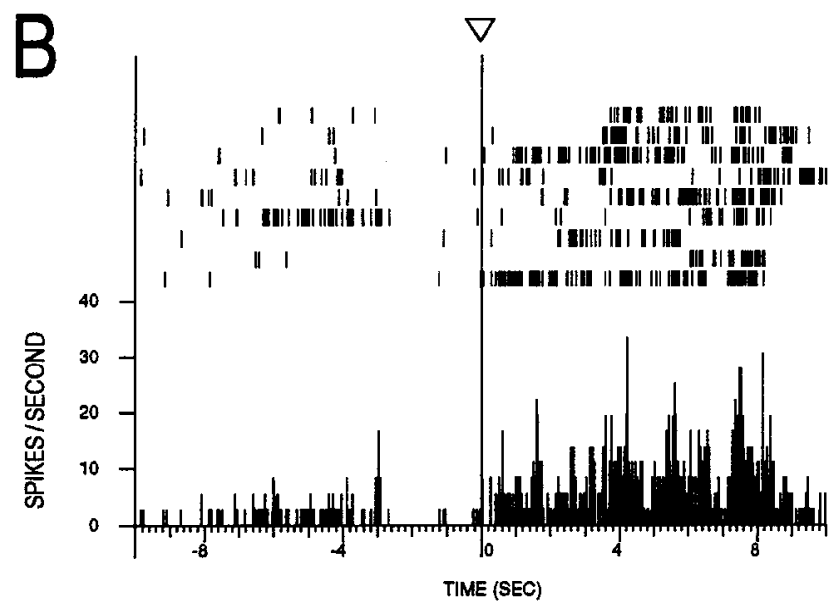

RAISE HEAD TOWARDS LEVER

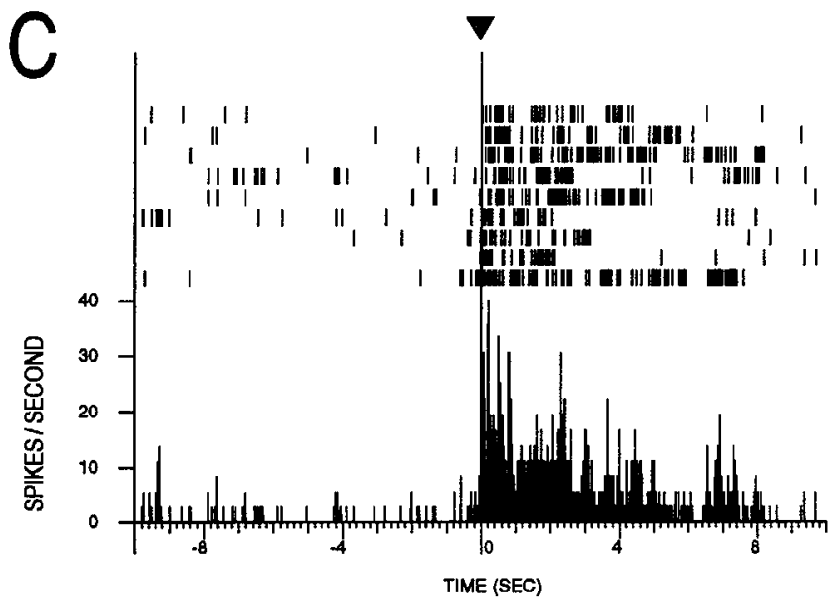

TOUCH LEVER

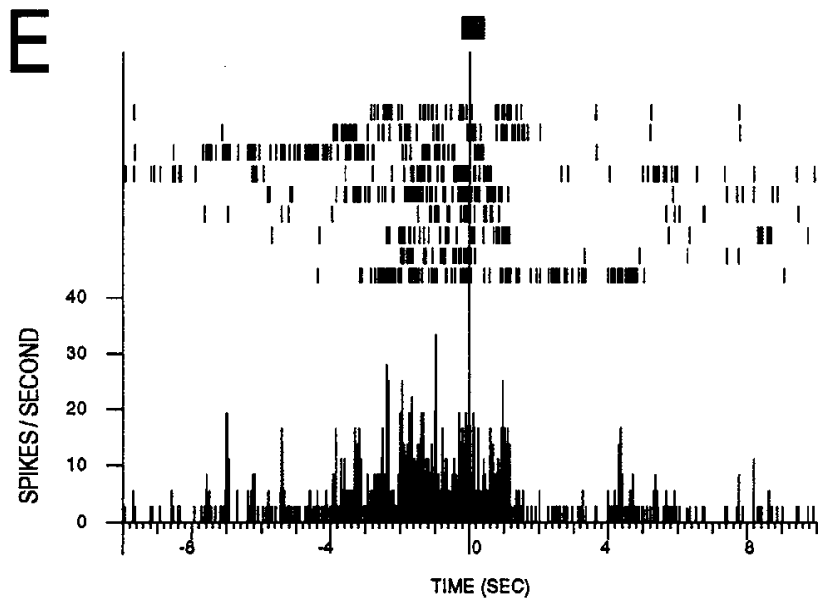

FORELIMB(S) RETURN TO FLOOR

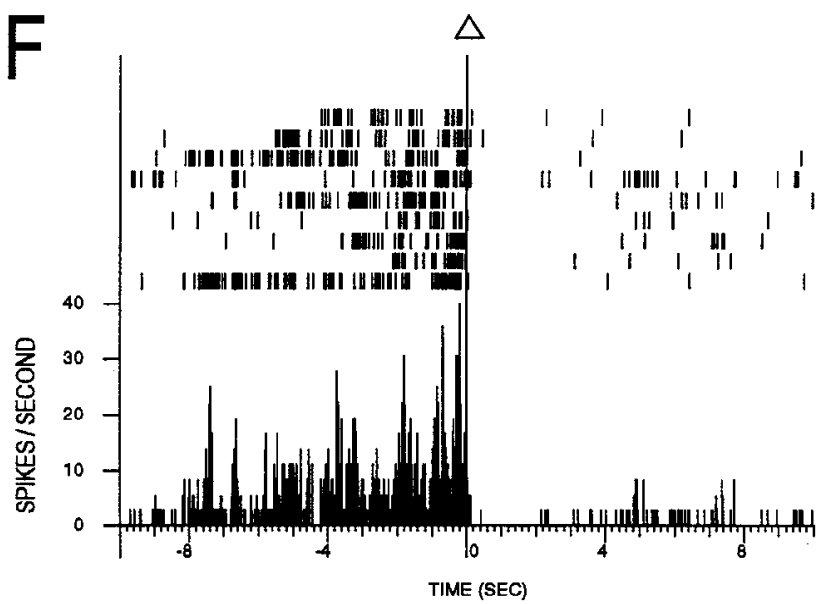

Figure 5. Raster plots and perievent histograms of the neuronal activity recorded during the cocaine self-administration trials shown in Figure 4. The six pairs of rasters and histograms in $A-F$ are centered around one of the six different fractionated behaviors related to orienting toward and pressing of the lever. The symbol at time zero above each pair of graphs represents the onset of the behavior that was used as the node for the graphs. These symbols correspond to the same behavior symbols as in Figure 4. The raster and histogram in $C$ clearly show the onset of this excitatory, lever press-related anticipatory response occurred as the animal raised its head toward the lever. The elevated firing rate ended promptly, coinciding with when the animal's forelimbs returned to the floor after pressing the lever, as shown in $F$. 
audible closing of the lever switch. Animals occasionally failed to press the lever with sufficient force to close the switch. In these instances, the animals were apparently alerted to the absence of the audible closing of the switch, and pressed the lever again within a few seconds (Fig. 4B).

Detailed video analysis of these behavioral categories was performed for selected trials in 13 experimental sessions in which a neuron exhibited an anticipatory response. This detailed examination of correlations between behavior and neuronal activity revealed an additional means of categorizing anticipatory responses. Examples of excitatory-anticipatory responses of an NAS neuron in relation to the fractionated lever-pressing behaviors during nine trials of a self-administration session are shown in Figure $4 A$. In this case, firing rates during "turning to lever" $(0.65 \pm 0.33 \mathrm{~Hz}, n=8)$ and "facing lever" ( $0.86 \pm 0.19$ $\mathrm{Hz}, n=8$ ) were not statistically different from firing rates during control stereotyped behaviors $(0.57 \pm 0.21 \mathrm{~Hz}, n=9 ; p>0.05$, Tukey HSD test), measured during a $3 \mathrm{sec}$ interval beginning $100 \mathrm{sec}$ prior to each lever press. However, a substantial increase in firing rate did occur during "raising head to lever" (15.93 \pm $1.59 \mathrm{~Hz}, n=8 ; p<0.05)$, "rearing to lever" $(12.01 \pm 1.62 \mathrm{~Hz}$, $n=9 ; p<0.05)$, and "lever to floor" $(17.13 \pm 1.94 \mathrm{~Hz}, n=$ $9 ; p<0.05)$. Firing rates returned to control levels immediately after lever pressing during the "turning away from lever" phase $(1.54 \pm 0.50 \mathrm{~Hz}, n=9 ; p>0.05)$. Statistically significant differences in firing rate were not detected between the three phases of lever pressing in which the firing rate was elevated.

A more direct assessment of the relation between unit activity and movement is evident in raster plots of these data, presented in Figure $4 B$. Note the consistent phasic increase in firing rate associated with behaviors specific to pressing the lever (raising head to lever, rearing to lever, lever to floor). This increase also occurred during instances in which the lever was not pressed with sufficient force to close the switch (dotted lines in trials 6 and 9), but did not occur prior to or during the initial orienting in the direction of the lever (turning to lever, facing lever). Perievent histograms and rasters of these data are presented in Figure 5. These displays reinforce the conclusion that the elevated rates of spike activity began with "raising head to lever" and werc maintained during lever-pressing movements. Termination of the phasic neuronal activity took place soon after lever pressing, occurring with trial-to-trial variation either immediately before or after the forelimbs returned to the floor (Fig. $4 B$ ). Thus, while the onset of phasic activity anticipated the lever press, the termination of altered spike activity occurred shortly afterward. Because of the close temporal association between lever pressing and the alterations in firing rate, this type of response will be referred to as a "lever press-related anticipatory response."

Other neurons in the NAS exhibited a different type of anticipatory response, termed the "orienting-related anticipatory response," as illustrated in Figure 6. This example is also an excitatory-anticipatory response (i.e., an excitatory, orientingrelated anticipatory response). However, the occurrence of increased spike activity was not restricted to lever pressing. Rath$\mathrm{cr}$, the firing rate increased while the animal started turning toward the lever or was still in the context of stereotyped behavior, specifically, from up to 2 sec prior to orienting (trials 1 , 4,5 ) to up to $2 \mathrm{sec}$ after orienting (trials 2, 3, 6, 7) (Fig. 6B). For each trial, spike activity remained elevated until after the lever was successfully pressed. The earlier, orienting-related onset of this response distinguished it from the lever press-related
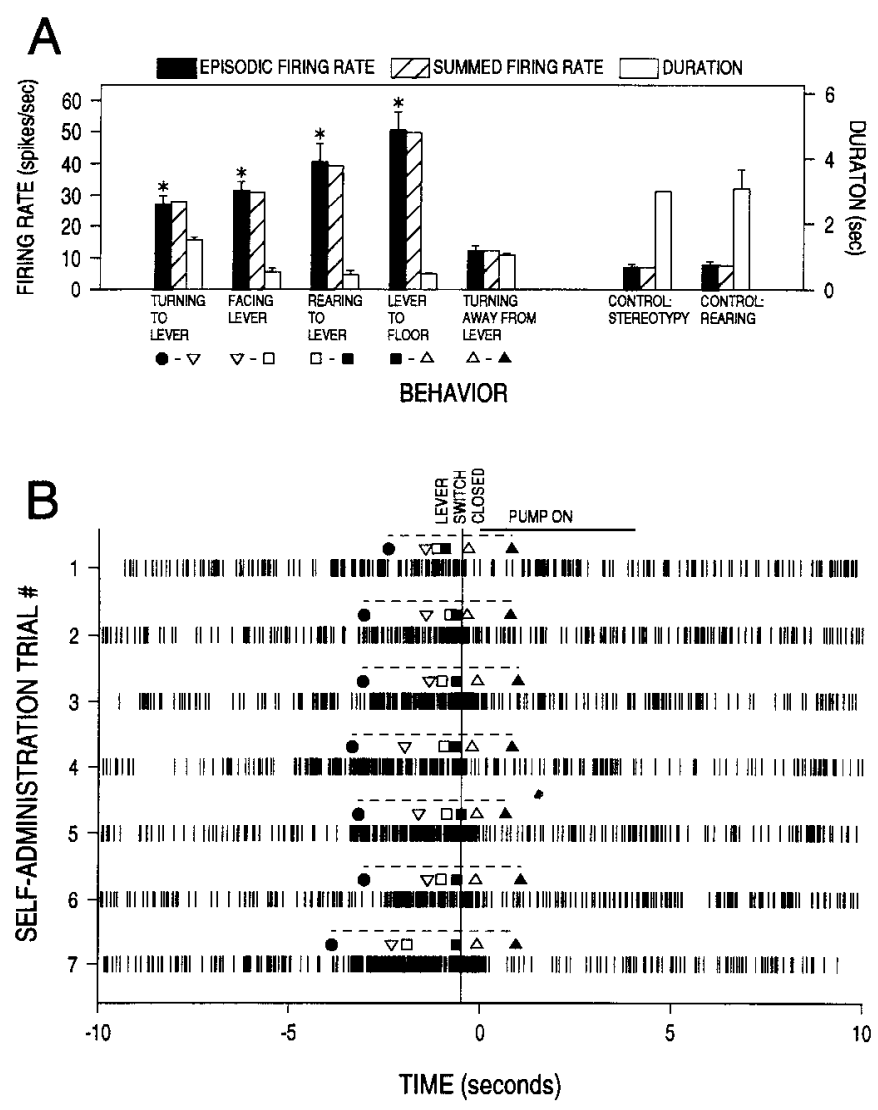

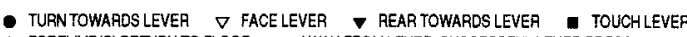
$\triangle$ FORELIMB(S) RETURN TO FLOOR \& AWAY FROM LEVER: SUCCESSFULL LEVER PRESS

Figure 6. Time course of altered spike activity for an excitatory, orienting-related anticipatory response by an NAS neuron, based on video analysis of lever-pressing behaviors during seven trials of a self-administration session. The format of this figure is identical to that of Figure 4 , except that there was no "raise head toward lever" category since this was not a clearly fractionated behavior for this animal. $A$, The increase in firing rates occurred as the animal oriented toward the lever. Firing rates continually increased as the animal approached and pressed the lever. Spike activity during these behaviors was significantly different from firing rates during the "Control: stereotypy" interval $(p<0.05$, Tukey HSD test, as indicated by asterisks above bars). The firing rate as the animal was "turning away from lever" decreased dramatically compared to during the "lever to floor" and did not differ statistically from firing rates during the control interval. $B$, Examination of raster display reveals that firing rates increased within $1 \mathrm{sec}$ of when the animal turned toward the lever, and sometimes occurred before turning (i.e., just prior to when the animal broke from stereotypy). Data were obtained from a different animal than in Figures 4 and 5.

anticipatory response. Raster plots and perievent histograms related to the fractionated behaviors provide an alternative view of the data, providing further evidence that the response began as the animal oriented toward the lever and terminated abruptly after the lever was pressed (Fig. 7).

Video analysis of an inhibitory, orienting-related anticipatory response is shown in Figure 8 . The inhibitory-anticipatory response of this neuron occurred during both orienting and lever press-related behaviors, beginning when the animal interrupted stereotypy and oriented toward the lever. Raster displays and perievent histograms confirmed that the response began as the animal oriented toward the lever and terminated soon after pressing the lever (Fig. 9).

Of the six excitatory-anticipatory responses subjected to video 

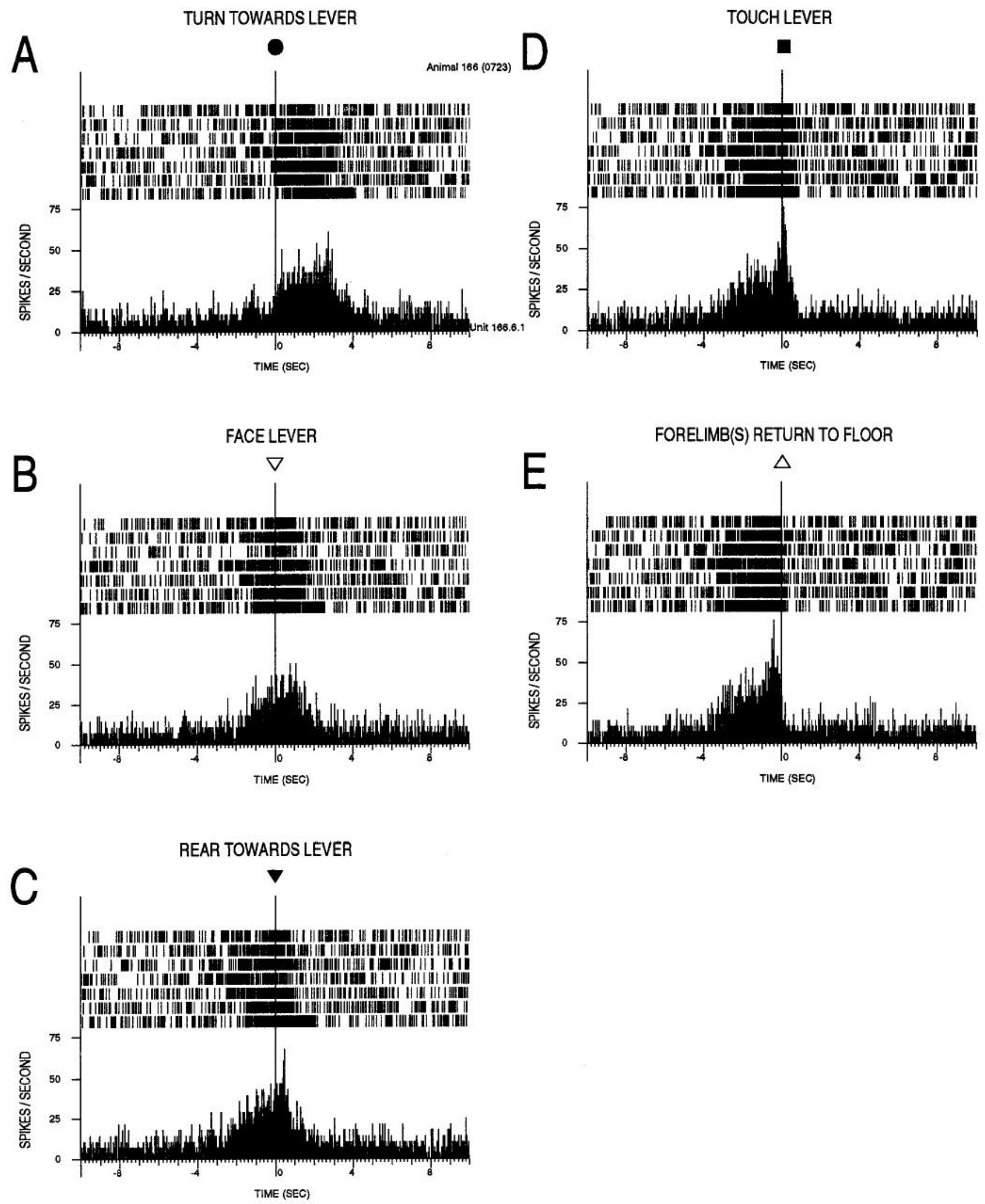

Figure 7. Raster plots and perievent histograms of the neuronal activity recorded during the cocaine self-administration trials shown in Figure 6. The format of this figure is identical to that of Figure 5. The five pairs of rasters and histograms in $A-E$ are each centered around one of five different fractionated behaviors related to orienting toward and pressing of the lever in the trials. These graphs show that the onset of the excitatory, orienting-related anticipatory response was centered around the time when the animal broke from stereotypy and oriented toward the lever ( $A$ ), whereas the response terminated abruptly as the forelimbs returned to the floor after pressing the lever $(E)$. 
analysis, three were of the orienting-related type and threc werc of the lever press-related type. In contrast, six of seven inhibitory-anticipatory responses were determined to be orientingrelated responses, with only one found to be a lever press-related response.

Anticipatory responses recorded across multiple self-administration sessions. The use of chronically implanted microwires permitted an evaluation of the development of changes in neuronal activity in the NAS across multiple sessions. Of particular interest is whether individual neurons in the NAS exhibited dynamic response properties as the animal learned the procedure of pressing a lever for cocaine self-administration. Such an assessment required that the strictest criteria be employed when evaluating whether the same neuron was recorded from the same microwire across experimental sessions. Even then the issue cannot be resolved with absolute certainty (see Materials and Mcthods). Nonetheless, in our experience with chronic microwire recording, extracellular action potentials recorded from neurons in the NAS (and dorsal striatum) with a signal-to-background ratio greater than 7 can be monitored for weeks or months, with every indication (constancy of waveform, firing rate and pattern, and signal-to-noise ratio) that the same unit has been monitored over this time. Response profiles from a neuron in the NAS that fulfilled these criteria during different self-administration sessions are presented in Figure 10, in which the anticipatory response developed over the course of several sessions and, once developed, persisted during all subsequent sessions.

\section{Relationship between anticipatory responses and movement}

It was necessary to determine if anticipatory responses were related to gross body movements in an obligatory way, independent of motivational and intentional aspects of self-administration of cocaine. This issue was examined in three ways.

First, rearing movements were a component of lever-pressing behaviors, and firing rates were altered during these rearing-type movements when they preceded ("anticipated") lever press. Similar rearing movements were also a prominent component of stereotyped behaviors when the animals were away from the lever, and were not related to lever pressing. Although the stereotyped rearing was not absolutely identical in form to rearing during lever pressing, the obvious similarity merited a comparison of spike activity during these two behaviors. If altered neuronal activity during lever pressing was related to particular aspects of the movements per se, then it would be expected that similar changes in neuronal activity would occur for both rearing at the lever and rearing when away from the lever (during stereotypy). For neurons with an anticipatory response, firing rates during rearing away from the lever were not statistically different from the control (nonrearing) stereotypy intervals, in contrast to the pronounced alteration in spike activity during rearinglike movements related to lever pressing for anticipatory responses (e.g., Figs. $4 A, 6 A, 8 A$ ).

Second, the orienting-related anticipatory responses began within seconds of initial orientation in the direction of the lever. Immediately after the lever was pressed, the animals usually moved away from the lever and stereotypy was reinstated, often turning so as to complete a circle; that is, a $360^{\circ}$ turn was accomplished in the sequence of stereotypy $\rightarrow$ lever pressing $\rightarrow$ reinstatement of stereotypy. Thus, turning toward and turning away from the lever often involved the same movements. Yet, for orienting-related anticipatory responses, firing rates during these similar movements were altered only when the animals
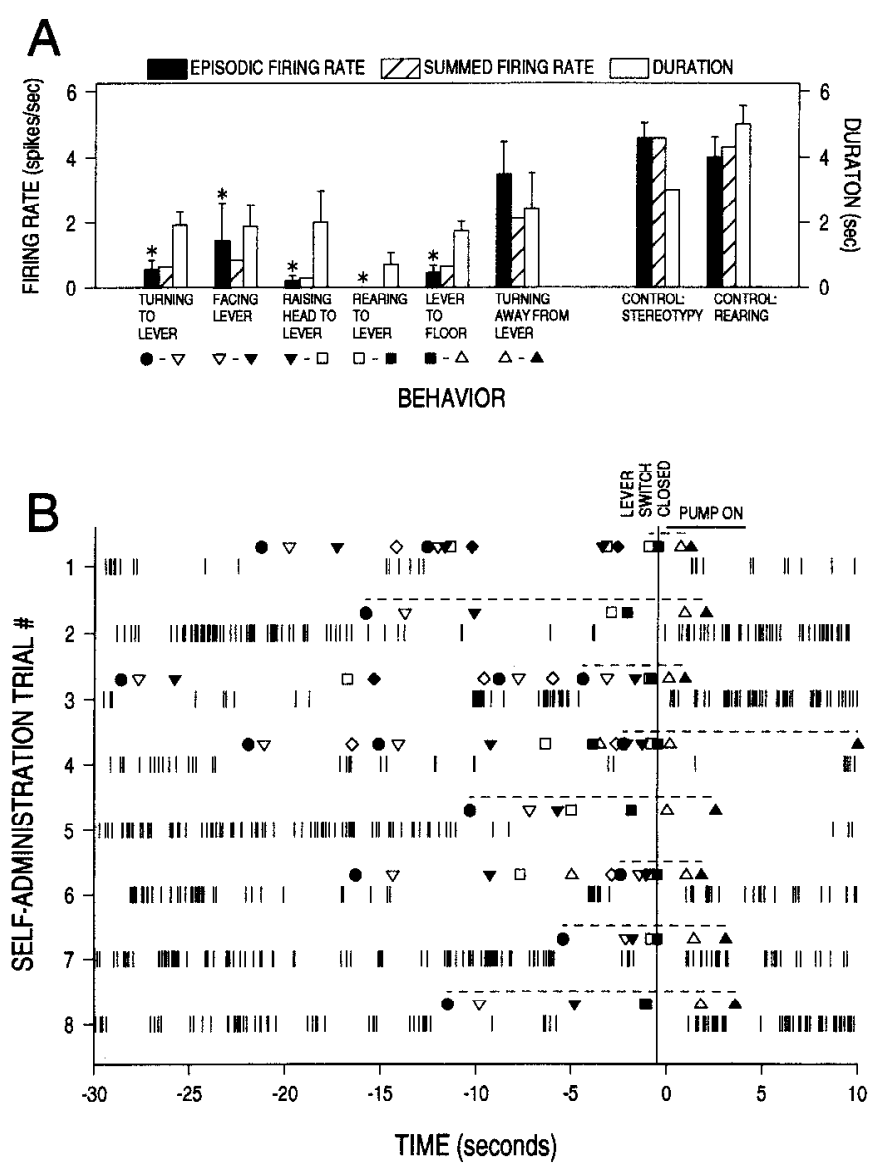

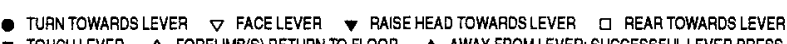
- TOUCHLEVER $\triangle$ FORELIMB(S) RETURN TO FLOOR $\triangle$ AWAY FROM LEVER: SUCCESSFUL LEVER PRESS - FOAELIMB(S) RETURN TO FLOOR: NO LEVER PRESS O TURN FROM LEVER: UNSUCCESSFUL OINO LEVER PRESS

Figure 8. Time course of altered spike activity for an inhibitory, orienting-related anticipatory response by an NAS neuron, based on video analysis of lever-pressing behaviors during eight trials of a self-administration session. The format of this figure is identical to that of Figure 4. $A$, Firing rates were depressed, compared to control stereotypy rates, during all behaviors related to orienting toward and pressing of the lever ( $p<0.05$, Tukey HSD test, as indicated by asterisks above bars). Firing rates returned to control levels only as the animal turned from the lever on its way to another side of the chamber as it prepared to reengage in stereotyped behaviors. $B$, Spike activity was decreased during sequences of behaviors that led to lever pressing (dashed lines). Data were obtained from a different animal than in Figures 4-7.

oriented toward and approached the lever (Figs. 6A, 8A), suggesting that this type of anticipatory response originated from a motivational drive rather than being obligatory to the movements. Furthermore, in some trials the orienting anticipatory response began while the animal was still engaged in stereotypy, seconds prior to orienting toward the lever, consistent with a motivational component to this response.

Third, neuronal activity of anticipatory units was evaluated with respect to general body movement by placing the animals on a treadmill that enslaved locomotion. Thirty minutes after the conclusion of cocaine self-administration sessions in which NAS neurons exhibited anticipatory responses, some animals were placed on a computer-controlled treadmill that had alternating cycles of $30 \mathrm{sec}$ on/30 sec off. Neuronal activity of these same neurons was continuously recorded during 20-35 min treadmill sessions. For five excitatory-anticipatory neurons tested, the firing rate when the treadmill was on (gross body move- 

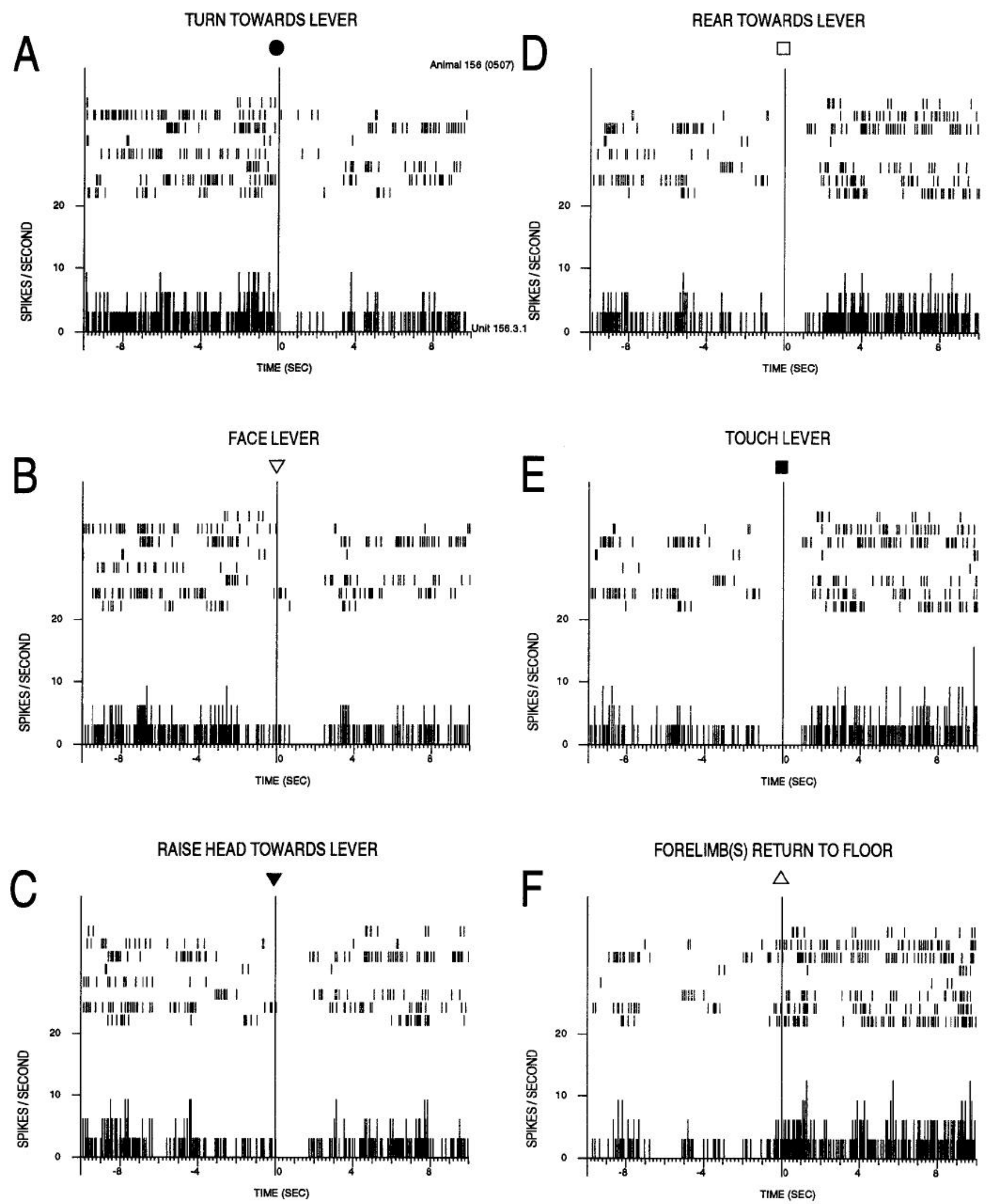

Figure 9. Raster plots and perievent histograms of the neuronal activity recorded during the cocaine self-administration trials shown in Figure 8 . The format is identical to that of Figure 5. The six pairs of rasters and histograms in $A-F$ are each centered around one of the six different fractionated behaviors related to orienting toward and pressing of the lever in the trials. The symbol at time zero above each pair of graphs represents the onset of the behavior that was used as the node for the graphs. These symbols correspond to the same behavior symbols as in Figure 8 . The onset of the inhibition was not clearly centered around a particular behavior, but can be seen to be prominent during the seconds after orienting toward the lever $(A)$. The phasic inhibition terminated soon after the lever was pressed, as the forelimbs return to the floor $(F)$. 

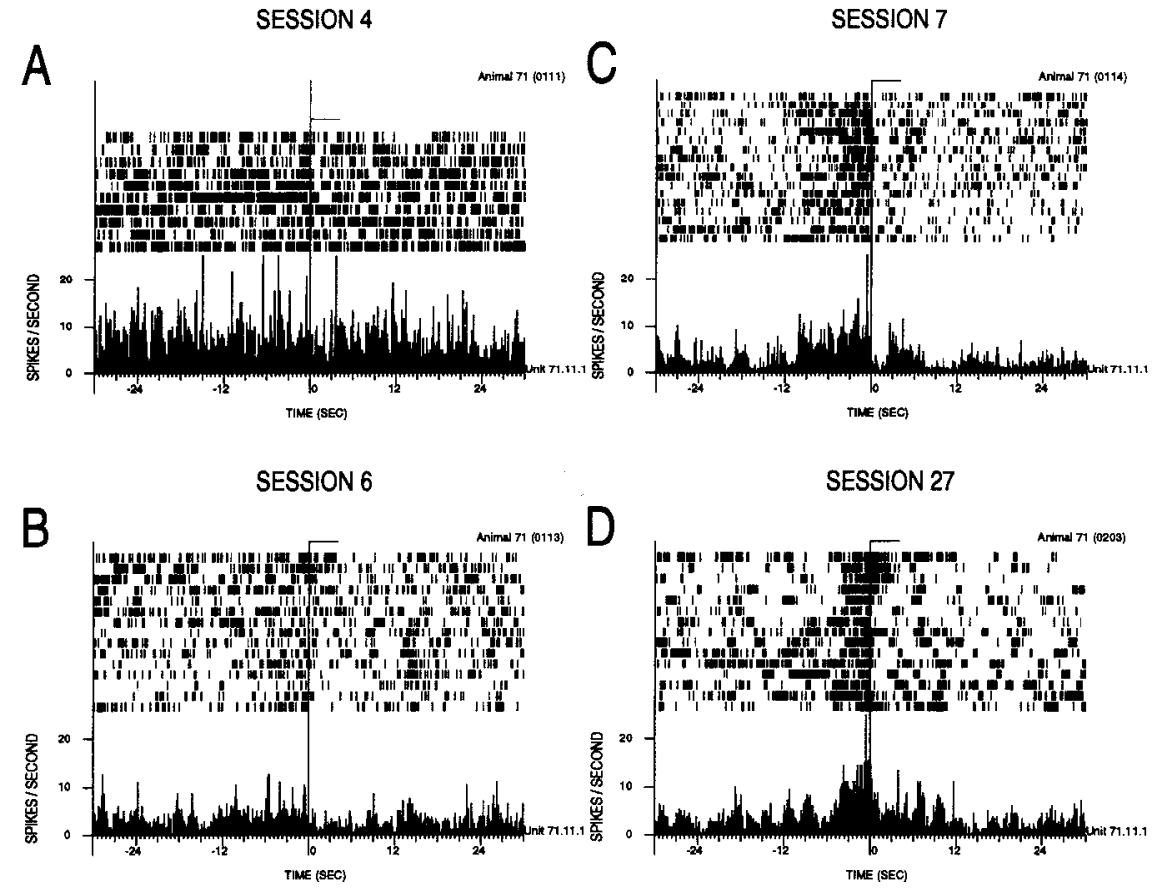

Figure 10. Perievent rasters and histograms of spike activity of a neuron across multiple self-administration sessions, showing the development of an excitatory-anticipatory response. During cocaine self-administration sessions $4(A)$ and $6(B)$, there were no indications of an anticipatory response. However, by session 7 an excitatory-anticipatory response became prominent $(C)$, starting about $10 \mathrm{sec}$ prior to lever pressing. This response was maintained in subsequent sessions, even $20 \mathrm{~d}$ later during session $27(D)$. It was inferred that the same neuron was monitored across these sessions using the criteria listed in Materials and Methods. Same neuron as shown in Figures 4 and 5; data in these latter figures were obtained during session 9 .
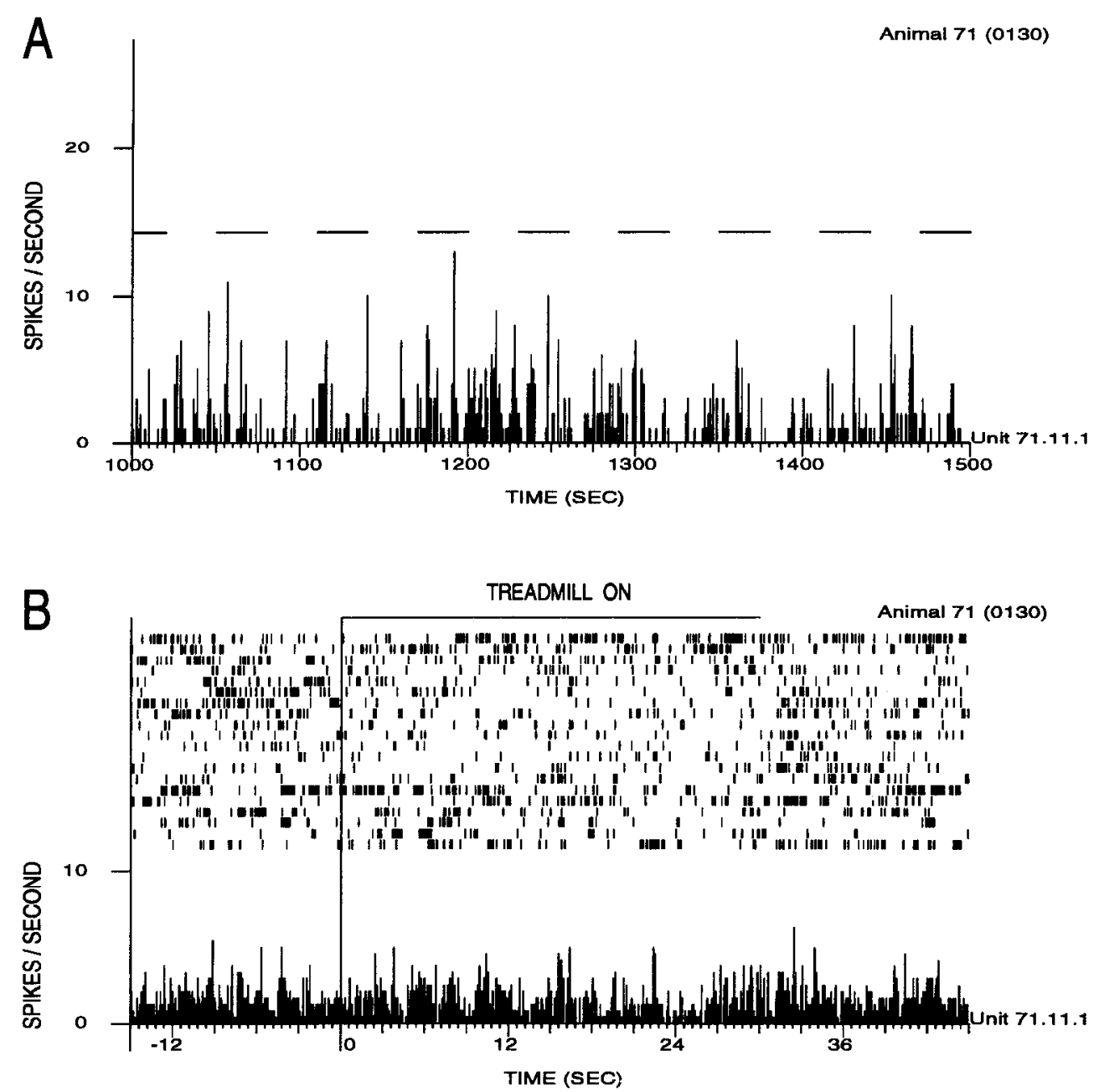

Figure 11. Neuronal activity of an excitatory-anticipatory neuron during a treadmill session (enslaved locomotion, no cocaine administration). An example of this neuron's anticipatory response is shown in Figures 4 and 5. A. Stripchart display of a $500 \mathrm{sec}$ segment (of a 2200 sec session) of spike activity during treadmill locomotion. The computer-controlled treadmill cycled through $30 \mathrm{sec}$ on $/ 30 \mathrm{sec}$ off trials. The horizontal bars in $A$ and $B$ indicate when the treadmill was on. $B$, A raster plot and perievent histogram of spike activity of the neuron shown in $A$ for the treadmill session. The time scale on the $\mathrm{x}$-axis is relative to the treadmill turning on (long vertical line at time zero). Note that there was no phasic alteration in unit activity during treadmill-enslaved locomotion, suggesting that this neuron's elevated activity during the anticipatory interval of cocaine self-administration was not secondary to gross body movements. 

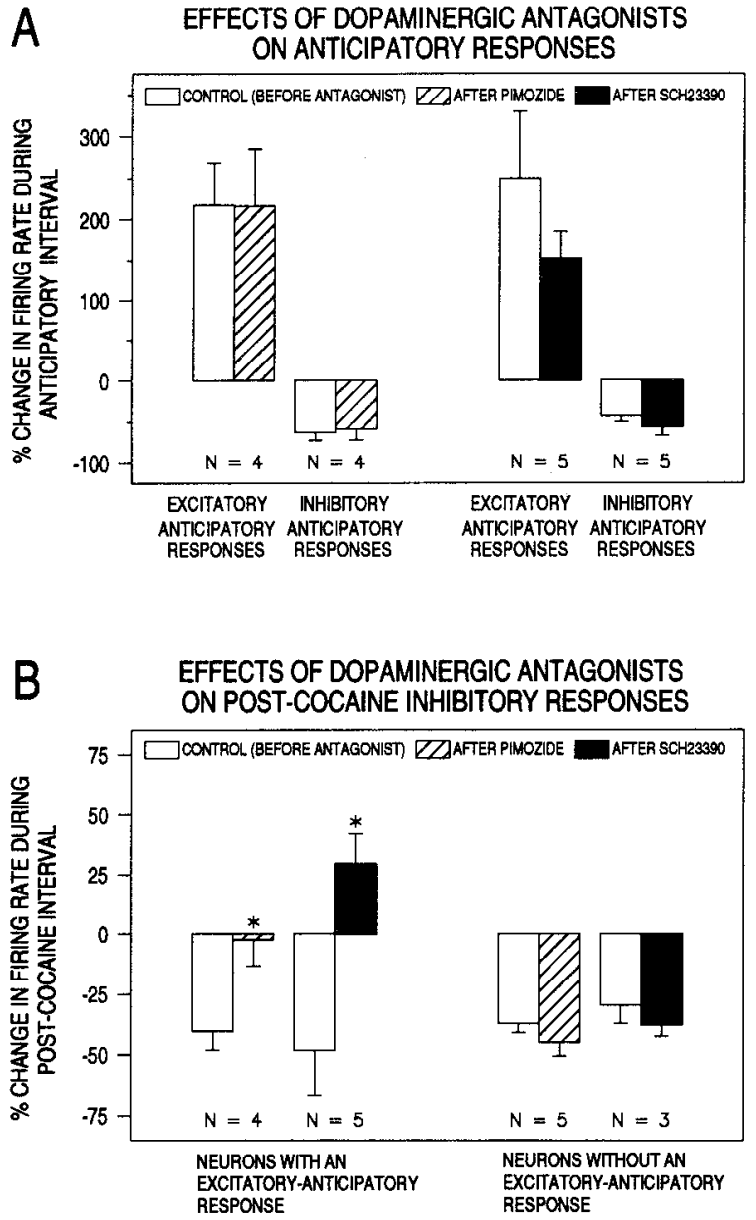

Figure 12. The effects of the dopamine $\mathrm{D}_{1}$ receptor antagonist $\mathrm{SCH}$ $23390(10-20 \mu \mathrm{g} / \mathrm{kg}, \mathrm{s} . \mathrm{c})$ and the $\mathrm{D}_{2}$ receptor antagonist pimozide $(0.25$ $\mathrm{mg} / \mathrm{kg}$, i.p.) on the response properties of NAS neurons during cocaine self-administration sessions. $A$, Effect of the dopamine antagonists on excitatory-and inhibitory-anticipatory responses. Neither pimozide nor SCH 23390 altered excitatory-or inhibitory-anticipatory response. There were no significant differences in pairwise comparisons ( $p>0.05, t$ test). $B$, Effects of SCH 23390 and pimozide on postcocaine inhibitory responses in two groups of neurons: those with an excilatory-anticipatory and postcocaine inhibitory response, and those with a postcocaine inhibitory response only. Pimozide effectively blocked the postcocaine inhibitory response of the excitatory-anticipatory group, and SCH 23390 reversed the postcocaine inhibitory response. However, neither antagonist affected the magnitude of postcocaine inhibition for neurons that lacked an excitatory-anticipatory response. Data presented as mean \pm $\mathrm{SEM} ; N$ is the number of neurons tested for each condition. Asterisks above bar graphs indicate statistically significant differences in firing rates compared to corresponding control condition ( $p<0.05, t$ test).

ments) was not significantly different from when the treadmill was off (rest) $(3.70 \pm 0.82$ and $3.41 \pm 0.75$, respectively, $n=$ $5 ; p>0.05, t$ test; Fig. 11). The two inhibitory-anticipatory neurons tested showed an increase in firing rate during the treadmill-on phase compared to the treadmill-off phase $(40 \%$ and $60 \%$ increases). These findings suggest the anticipatory responses observed during self-administration sessions were not related to generalized movements.

\section{Effects of dopamine receptor antagonists on anticipatory and postcocaine responses}

The $\mathrm{D}_{1}$ receptor antagonist $\mathrm{SCH} 23390(10$ or $20 \mu \mathrm{g} / \mathrm{kg}$, s.c.) or the $D_{2}$ receptor antagonist pimozide $(0.25 \mathrm{mg} / \mathrm{kg}$, i.p.) was in- jected either 20 min before selected cocaine self-administration sessions or during a session after 7-10 trials. Recording sessions lasted for $2-3 \mathrm{hr}$. These antagonist doses extinguish cocaine selfadministration without impairing movement (de Wit and Wise, 1977; Woolverton, 1986; Koob et al., 1987). Extinction is characterized by an initial increase in the rate of lever pressing eventually followed by a cessation of lever pressing. In this study, SCH 23390 was more effective than pimozide at inducing extinction during the time of the recording sessions. During the lever pressing phase of extinction, neither antagonist, given alone, significantly altered excitatory- or inhibitory-anticipatory responses, as summarized in Figure $12 \mathrm{~A}$.

The effects of the antagonists on the postcocaine responses were more complex. For neurons with both excitatory-anticipatory and postcocaine inhibitory responses, pimozide effectively blocked the postcocaine inhibition whereas SCH 23390 reversed the response from inhibition to excitation. However, the antagonists had no effect on postcocaine inhibition in neurons that did not have anticipatory responses (Fig. 12B). Figure 13 illustrates the lack of effect of pimozide on an excitatoryanticipatory response and the suppression of postcocaine inhibitory responses, and Figure 14 shows a case in which $\mathrm{SCH}$ 23390 did not interfere with an inhibitory-anticipatory response.

\section{Histology}

The location of 76 neurons was reconstructed histologically. As shown in Figure 15, 60 (79\%) of the reconstructed recording sites were located in the core region of the NAS and $16(21 \%)$ were in the shell. There were 25 anticipatory neurons in the core and 3 in the shell. Of the inhibitory-anticipatory neurons, 14 were in the core and 1 was in the shell; 11 of the excitatoryanticipatory neurons were in the core and 2 were in the shell. Of the nonanticipatory neurons, $35(73 \%)$ were in the core and 13 were in the shell. The proportions of excitatory-anticipatory, inhibitory-anticipatory neurons, and nonanticipatory neurons in the core and shell regions of the NAS were not statistically different $\left(\chi^{2}=3.17, v=2 ; p>0.05\right)$. Likewise, when anticipatory neurons were grouped together, their distribution in the core ( 25 of $28,89 \%$ ) was not significantly different from the distribution of nonanticipatory neurons $\left(\chi^{2}=1.95, v=1 ; p>0.05\right)$.

\section{Discussion}

An important issue raised by the hypothesized role of the NAS in drug self-administration (Koob and Bloom, 1988; Wise, 1989; Pulvirenti et al., 1991) is the nature of the neurophysiological substrates that contribute to the expression of this behavior. If the NAS participates in regulating the sequence of motor acts that achieve drug acquisition and lead to reinforcement of behavior (Wise, 1989; Wise and Hoffman, 1992), then alterations in spike activity by neurons in the NAS would be expected to occur prior to self-administration. In contrast, if the NAS were to have only a role in the reinforcing or "reward" qualities of cocaine, it would be expected that altered neuronal activity in the NAS would be found only after administration of cocaine when the drug activated such mechanisms.

The results of this study provide three lines of neurophysiological evidence that suggest the NAS is an important region for the initiation and mediation of cocaine self-administration behaviors. First, a population of neurons in the NAS was found to exhibit altered levels of spike activity during the seconds immediately preceding lever pressing for intravenous admin- 

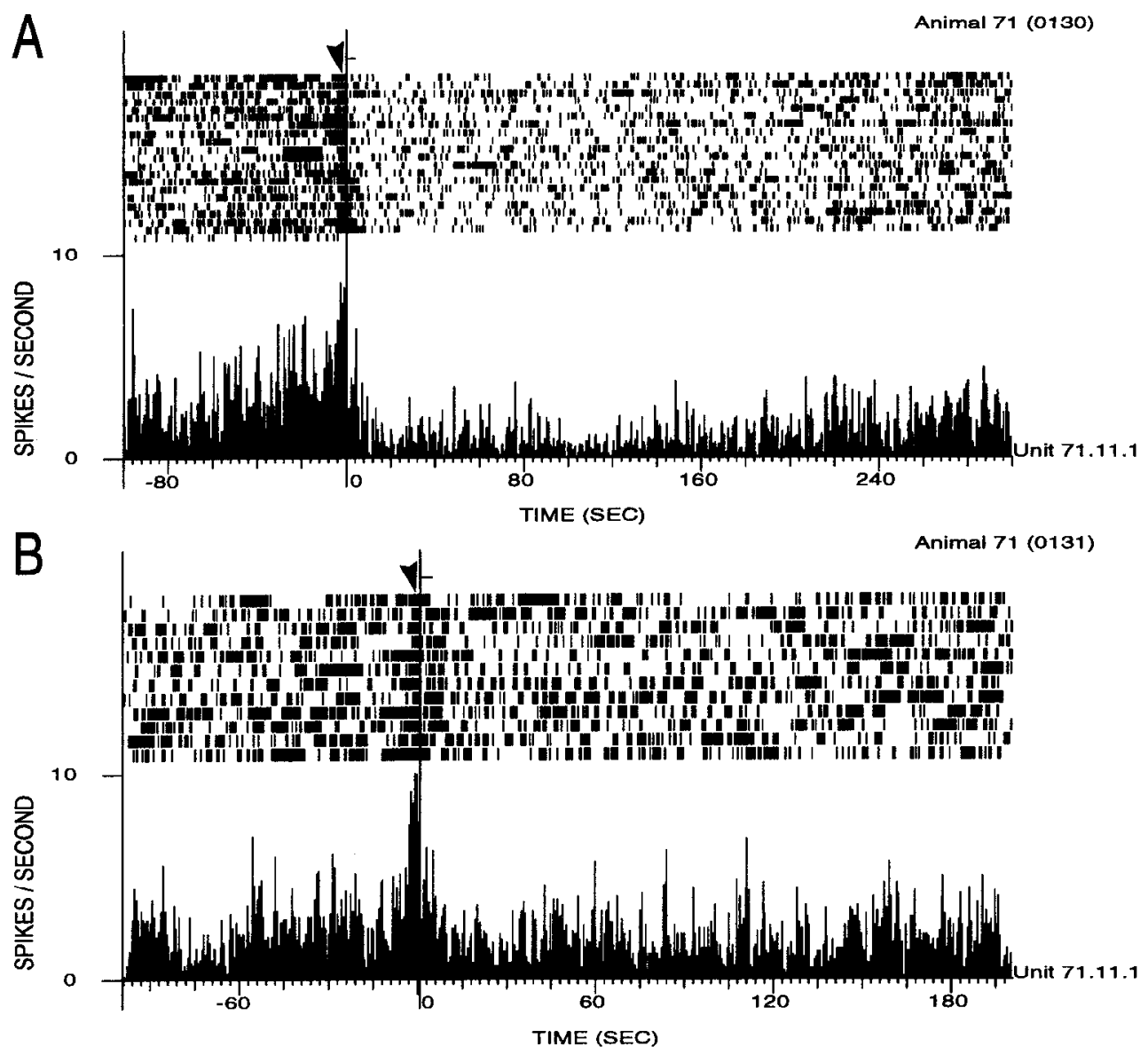

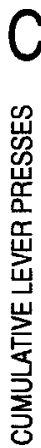

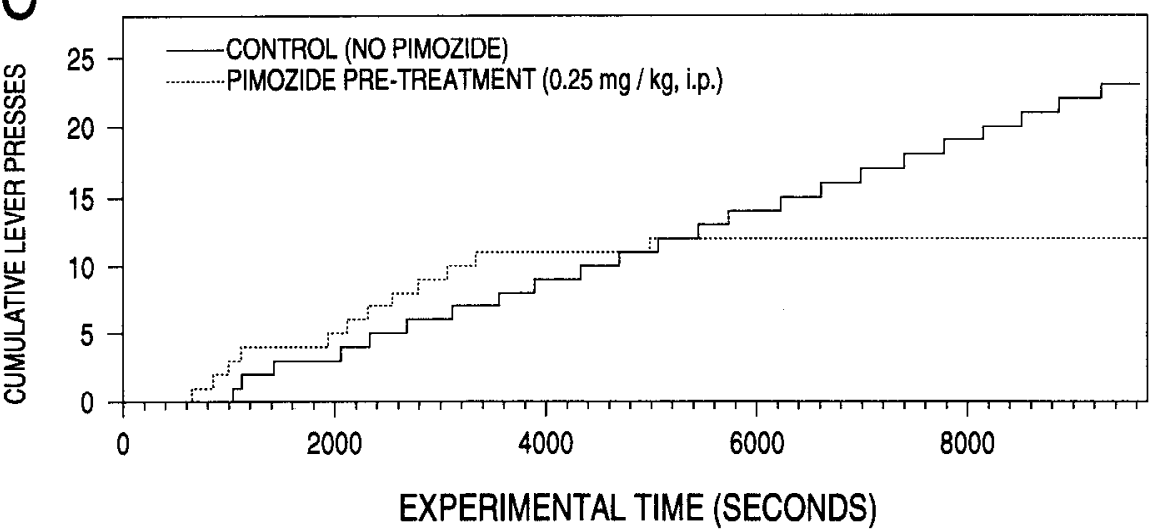

Figure 13. Raster plots and perievent histograms showing the effect of pimozide, a $\mathrm{D}_{2}$ receptor antagonist, on the cocaine self-administration responses of a neuron in the NAS that exhibited both an excitatory-anticipatory and postcocaine inhibitory response. $A$, In the absence of pimozide, a prominent postcocaine inhibition persisted for about 4 min after cocaine self-administration. The excitatory-anticipatory response is evident in the graphs, occurring a few seconds before lever pressing (arrowhead). $B$, The following day pimozide $(0.25 \mathrm{mg} / \mathrm{kg}$, i.p.) was administered $20 \mathrm{~min}$ prior to the beginning of the cocaine self-administration session. Same neuron as in $A$ (inferred from criteria listed in Materials and Methods). Note the intact excitatory-anticipatory response (arrowhead) and the reduction of the postcocaine inhibitory response. On the following day, in which no antagonist was given, the postcocaine inhibition was again prominent for this neuron during the self-administration session (data not shown). Different time scales were used for graphs in $A$ and $B$, due to the shorter interpress interval during the initial stages of pimozide-induced extinction and the long time course of postcocaine inhibition in $A . C$, Cumulative histogram of lever pressing during the experimental sessions shown in $A$ and $B$. In the absence of pimozide, lever pressing occurred in regularly spaced intervals, about every $6 \mathrm{~min}$ (solid line). When pretreated with pimozide, lever pressing became irregular as extinction developed, characterized by an initial increase in the rate of lever pressing followed by total cessation of lever pressing. istration of cocaine, that is, "anticipatory" responses. Second, in the minutes following cocaine administration, many neurons in the NAS, including most of the neurons with anticipatory responses, had altered firing rates, similar to previous reports in anesthetized animals. Third, these anticipatory and postcocaine responses were differentially affected by dopaminergic receptor antagonists. Prior to the extinction of cocaine selfadministration produced by these agents, the anticipatory responses were unaltered by either $D_{1}$ or $D_{2}$ receptor antagonists whereas postcocaine inhibition was blocked in a subset of neurons with anticipatory responses.

\section{The behavioral paradigm and anticipatory responses}

The behavior studied in this paradigm was restricted to a form of operant conditioning in which the rat learned to press a lever in order to satisfy a requirement to obtain cocaine. A critical aspect of the paradigm was the self-initiation of lever pressing episodes as opposed to being cued by the experimenter. Superficially, the behavior appeared simple in that the rat pressed a lever that led to intravenous cocaine infusion followed by a period of cocaine-induced stereotyped behaviors. Stereotypy was maintained for 5-10 min, at which time an internal trigger caused the animal to interrupt stereotypy to engage in behaviors specific for orienting toward and pressing the lever. The underlying assumption was that an internal sequence of states of neural activity drove this behavior, since there were no external timing cues in the experimental paradigm. The presence of different temporal phases of altered firing rates in NAS neurons in the seconds prior to lever pressing during cocaine self-administration (e.g., orienting-related vs lever pressing-related anticipa- 
Figure 14. Effect of SCH 23390, a D receptor antagonist, on cocaine self-administration responses by a neuron in the NAS. The format of this figure is similar to that of Figure 13. A, Prior to injection of $\mathrm{SCH} 23390$, this neuron had an inhibitory-anticipatory response (arrowhead), with no significant change in firing rate during the postcocaine interval. $B, \mathrm{SCH} 23390(10 \mu \mathrm{g} /$ $\mathrm{kg}$, s.c.) was injected at $3760 \mathrm{sec}$ into the session. Note the maintenance of the inhibitory-anticipatory response (arrowhead) following the injection of the antagonist. $C$, Cumulative histogram of lever pressing for cocaine during the experimental session shown in $A$ and $B$. Prior to administration of $\mathrm{SCH}$ 23390 , lever pressing occurred in regularly spaced intervals, with an average interpress interval of $267 \mathrm{sec}$. Following SCH 23390 , the rate of lever pressing more than doubled, with an average interpress interval of $108 \mathrm{sec}$. Data were obtained from a different neuron than in Figure 13.
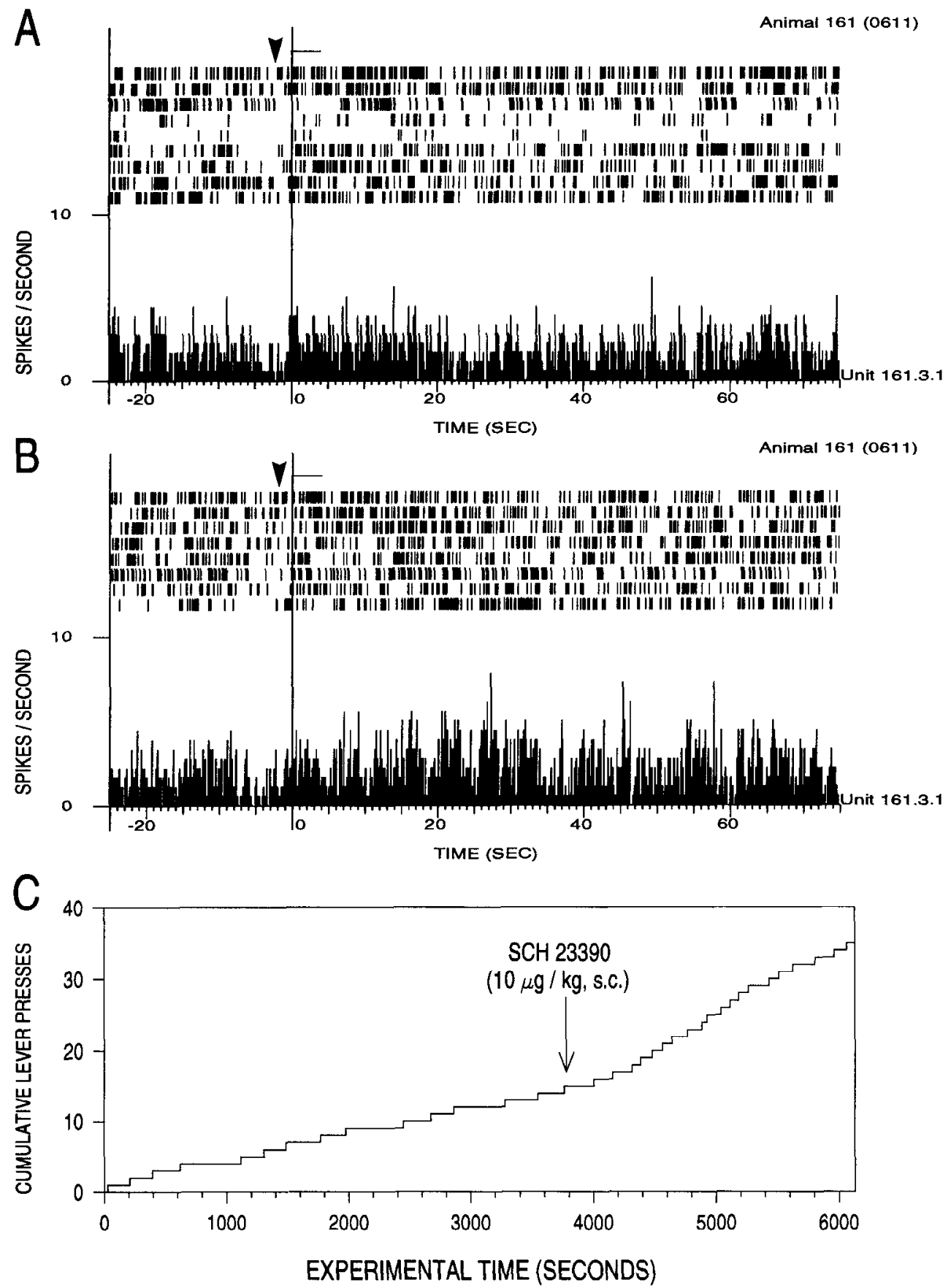

tory responses) demonstrates that such a sequencing of neural events indeed took place, and the distinctly different timing of these anticipatory events suggests that independent states were generated. In some cases reciprocal excitatory and inhibitory responses were temporally coincident, but the presence of local network properties in the NAS (e.g., inhibitory recurrent collaterals of medium spiny neurons) may allow these different responses to be driven by a common process.

Anticipatory responses were divided into two categories based on behavioral correlates determined from extensive cxamination of video records, as summarized schematically in Figure 16. The "orienting-related" anticipatory response consisted of sustained alterations in firing activity with an onset centered around self-generated interruption of stereotypy and persisted throughout the sequence of movements that culminated in pressing the lever. The other major category of behaviorally correlated response, the "lever pressing-related anticipatory response," occurred with a tight temporal relation to the sequences of movements directly related to lever pressing.

These different response profiles may represent an important segregation of roles for the NAS in self-administration of cocaine and "reward" mechanisms in general. The orienting-related anticipatory response may be indicative of a "trigger" mechanism that functions to initiate movement sequences directed toward attainment of reward. In contrast, the lever pressing-related anticipatory response may be indicative of a motor execution mechanism consisting of a serial chain of signals from afferents converging in the NAS. One might assume that the transition 


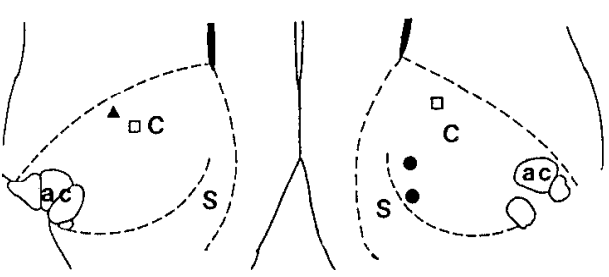

Bregma $2.20 \mathrm{~mm}$

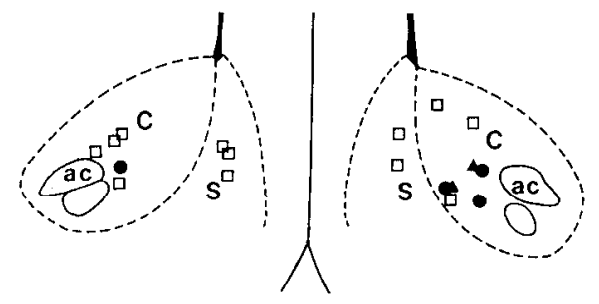

Bregma $1.70 \mathrm{~mm}$

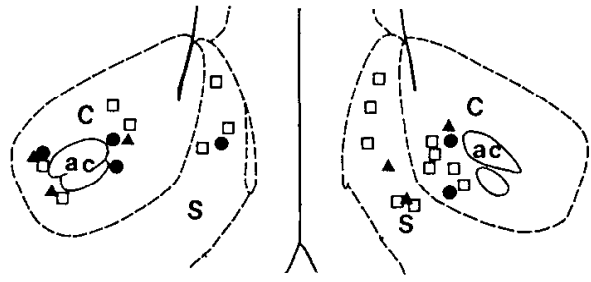

Bregma $1.20 \mathrm{~mm}$
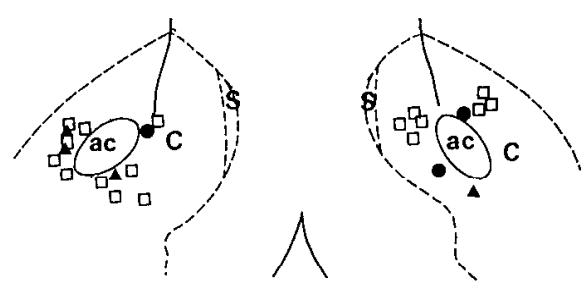

Bregma $0.70 \mathrm{~mm}$
Figure 15. Histological localization of 76 neurons recorded with chronically implanted microwires. Schematic outlines of the nuclear boundaries of the NAS were modified from the rat brain atlas of Paxinos and Watson (1986); coordinates shown are also from this atlas. $C$, core area of the NAS; $S$, shell area of NAS; ac, anterior commissure. Boundaries of core and shell are represented by dashed lines. Response properties of neurons are labeled as follows: solid triangles, excitatory-anticipatory response; solid circles, inhibitory-anticipatory response; open squares, nonanticipatory response. Due to the larger volume of the corc, the majority of recordings (60 of 76 neurons, $79 \%$ ) were from this area. The distribution of anticipatory responses ( 25 of 28 , or $89 \%$, in core) versus nonanticipatory neurons ( 35 of 48 , or $73 \%$, in core) in core and shell was not statistically different $\left(\chi^{2}=1.95, v=1 ; p\right.$ $>0.05$ ). from stereotypy to orienting toward the lever represents the first sign of a motivationally driven change in behavior. One concept is that neurons that became active during this alteration in behavioral set, as exemplified by neurons with orienting-related anticipatory responses, are candidate trigger systems activated by a motivation to obtain reward. The lever pressing-related anticipatory response occurred later in the behavioral sequence, and may correspond to a transformation in time of internal motivational drives into components of a sustained motor plan functioning to acquire reward (in this case, presumably a euphoric state elicited by cocaine). An interpretation of these leverpressing anticipatory responses is that they are components of a motor execution system to obtain reward. The concept of different systems would lead us to hypothesize the existence of separate cortico-striato-thalamo-cortical loops to mediate these functions. It is important to note that at this time only $13 \mathrm{neu}-$ rons have been categorized with detailed video analysis with respect to onset and termination times of spike activity during self-administration sessions. We anticipate that additional categories of neurons based on functional attributes will be recognized as this form of analysis is extended throughout the dorsal and ventral striatum, and to different cortical regions.

It appears that the immediate action of cocaine is to suppress lever pressing. This occlusion of responding may be related to "satiation," may be due to an induction of stereotypy that displaces other behavioral options, or may be a simple suppression

\section{NEURONAL ACTIVITY IN RELATION TO COCAINE SELF-ADMINISTRATION}

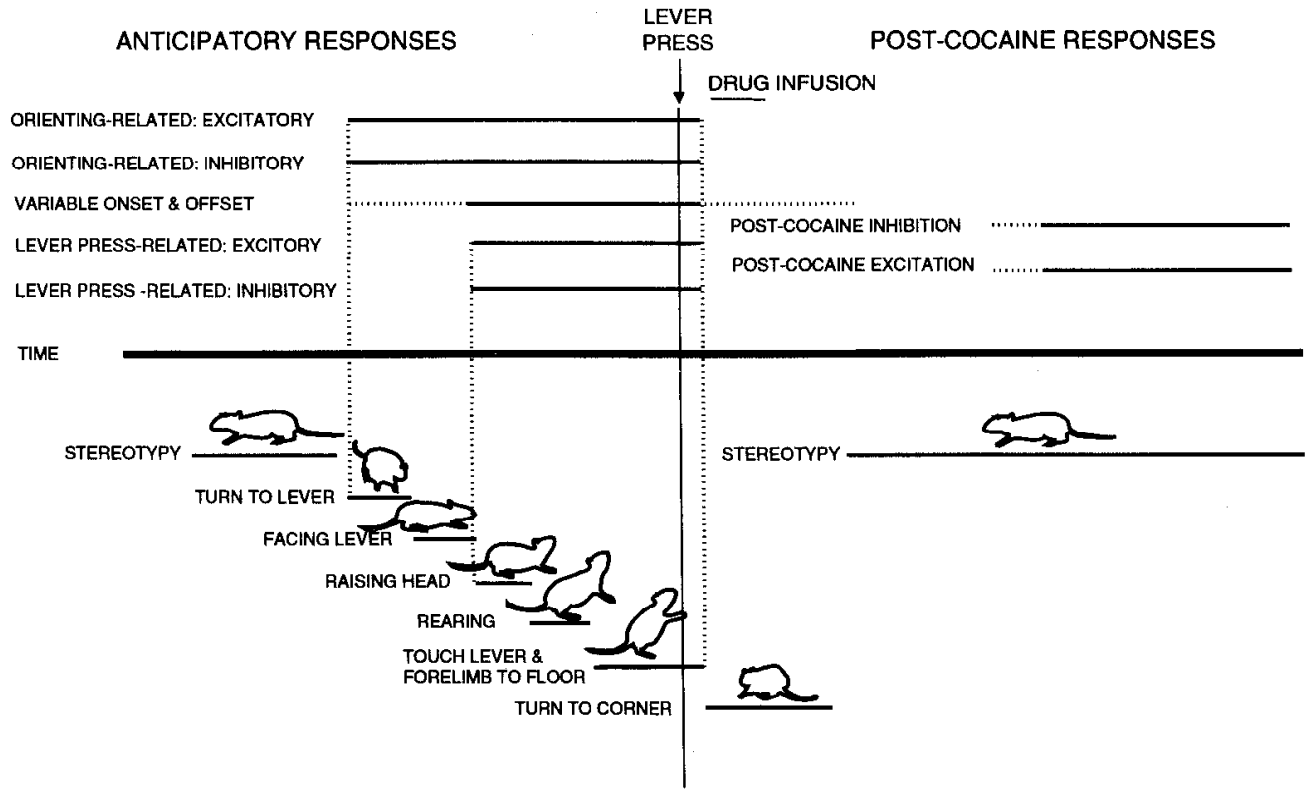

Figure 16. Schematic sumary of types of neuronal activity recorded in NAS during self-administration of cocaine. Solid horizontal lines for neural activity indicate a distinct time of onset or termination with respect to the corresponding behavior as scored from video records. Horizontal dashed lines indicate a variable onset or termination in relation to observable behavior. 
of the specific neural mechanism(s) for the trigger. However, Wise et al. (1977) have shown that rats are able to press a lever during amphetamine-induced stereotypy. The effects of the lessening of cocaine's neuropharmacological effects, for example, blocking uptake of monoamines or decreasing spike activity by monoaminergic neurons, may activate an internal trigger for changing from stereotypy to orienting and lever-pressing behaviors. The idea of an internal condition crossing a threshold is consistent with (1) the relatively short (20-25 min) half-life of intravenously administered cocaine in blood and brain (Nayak et al., 1976), (2) the rate of cocaine self-administration decreasing with larger doses of cocaine (Pickens and Thompson, 1968), and (3) rats self-administering cocaine at a rate that maintains an elevated level of extracellular dopamine in the NAS (Pettit and Justice, 1989, 1991) as measured by microdialysis. However, the specific correlation with dopamine levels is unclear since Hurd et al. (1989) did not detect increased levels of in extracellular dopamine concentration in the NAS during cocaine self-administration with repeated exposure of the drug. The limited time resolution of microdialysis may not adequately assess transient changes in extracellular dopamine levels between lever presses.

Finally, it could be argued that the anticipatory responses were related to movement and locomotion per se but not to motivational states. We would argue against this notion for three reasons. First, the most direct evidence comes from the observation that patterns of movement similar to but unrelated to lever pressing, for example, spontaneous rearing during stereotypy when the animal was away from the lever, did not elicit altered firing activity in neurons that expressed these types of anticipatory responses. Second, the animals often made the same sequence of movements as they turned toward the lever to press it as when, after having pressed the lever, they turned away from the lever to reengage in stereotypy, thereby completing a $360^{\circ}$ turn. Altered spike activity was confined to the turning toward the lever $\left(0-180^{\circ}\right)$, but did not occur when the animal turned from the lever and reengaged stereotypy $\left(180-360^{\circ}\right)$. Third, the firing rate of these neurons was largely unchanged during treadmill-enslaved locomotion, indicating that gross body movements were not likely to account for altered firing rates during anticipatory responses.

\section{Postcocaine responses}

Almost one-half ( $48 \%$ ) of the neurons in NAS had altered firing rates, typically inhibited, in the minutes following intravenous administration of cocaine, as might be expected if the NAS is a site critical to the reinforcement of cocaine self-administration. The ramp-like return to baseline firing rates of some neurons in the NAS during postcocaine inhibition proved to be a good predictor of the next lever press (see Fig. 3). In preliminary studies, we found that higher doses of cocaine produced longer periods of inhibition that coincided with a longer self-administration interval, with the return to baseline firing rates for such units providing an accurate predictor of subsequent self-administration events (J.-Y. Chang, S. F. Sawyer, R.-S. Lee, and D. J. Woodward, unpublished observations). The predominance of inhibitory postcocaine responses observed in this study was similar to those reported with in vivo extracellular recordings in anesthetized animals (White et al., 1987). A smaller fraction of NAS neurons exhibited an increase in firing following exposure to cocaine. Since the time course of postcocaine excitation overlapped with that of postcocaine inhibition, these responses may be due in part to different pharmacological effects of cocaine on these neurons, or to local reciprocal circuit effects arising from inhibitory axon collaterals or inhibitory interneurons.

\section{Dopamine neurotransmission in anticipatory and postcocaine responses}

The possible involvement of dopaminergic mechanisms in anticipatory and postcocaine neuronal responses in the NAS was tested by administering $\mathrm{D}_{1}(\mathrm{SCH} 23390)$ or $\mathrm{D}_{2}$ (pimozide) dopamine receptor antagonists prior to or during self-administration of cocaine. The doses of the antagonists used in the present study were based on the results of previous studies of cocaine self-administration in rats in which these antagonists extinguished self-administration of cocaine but did not interfere with movements (de Wit and Wise, 1977; Koob et al., 1987). In this study, as in others (cf. Le Moal and Simon, 1991), extinction of lever pressing for cocaine was observed following systemic injection of dopamine receptor antagonists. Anticipatory responses were not significantly altered by either antagonist. Likewise, the postcocaine response of units that did not have anticipatory responses were unaffected. However, the postcocaine inhibition of neurons that had an excitatory-anticipatory response was blocked by pimozide and slightly reversed toward excitation by SCH 23390. Neurons with both inhibitory-anticipatory and postcocaine responses were observed too infrequently to be tested with the antagonists.

The apparent specific action of dopamine receptor antagonists on a subset of neurons with postcocaine inhibition suggests that the functional role of dopaminergic neurotransmission may be uniquely related to regulation of the reinforcing mechanisms that support the operantly conditioned task. In contrast, the inability of dopaminergic receptor antagonists to block postcocaine inhibitory responses in neurons that did not have anticipatory responses suggests the existence of independent mechanisms for producing this inhibition. We have also observed that operant and nonoperant (passive) administration of cocaine produce similar degrees of postcocaine inhibition when administered at the same doses and similar schedule (random intervals of 5-10 min; Chang, Sawyer, Lee, and Woodward, unpublished observations), thereby providing evidence that the direct responses to cocaine during self-administration werc mediatcd by neural activity evoked via a pharmacological action rather than being part of neural circuit that was specifically engaged during the conditioned response. It should be noted that the doses for dopamine receptor antagonists used for this study were relatively low and did not disrupt locomotor behavior. The involvement of non-dopaminergic effects of cocaine in the NAS, for example, on uptake of other monoamines (Broderick, 1991), has yet to be evaluated electrophysiologically in awake animals.

In summary, the nature of neuronal activity within the NAS during cocaine self-administration and the effects of dopamine receptor antagonists suggest that the NAS may be involved in the mediation of cocaine self-administration behaviors through at least two different, segregated mechanisms. First, the NAS may serve as an initiator of behaviors necessary for the acquisition of rewarding drugs, as represented by anticipatory responses, a mechanism that is not critically dependent on dopaminergic transmission. Second, the NAS may participate mechanisms of reinforcement activated by cocaine to sustain the operant conditioning. These effects may be subject to blockade by dopamine receptor antagonists. 


\section{Inputs to the nucleus accumbens}

The issue arises as to what regions provide afferents to the NAS that might elicit the characteristics of responses found in this study. The NAS has been subdivided into "core" and "shell" regions (Zaborszky et al., 1985). The shell receives input from the subiculum (Groenewegen et al., 1987), midline thalamus (Berendse and Groenewegen, 1990), and amygdala (Kelley et al., 1982) and projects to ventromedial ventral pallidus (which innervates mediodorsal nucleus and the VT $\Lambda$ ), VTA, lateral hypothalamus, and the pedunculopontine nucleus (Zahm and Heimer, 1990). In contrast, the core's afferents include prefrontal cortex (Berendse et al., 1992a), midline thalamus (Berendse and Groenewegen, 1990), and amygdala (Kelley et al., 1982), with efferent projections to dorsolateral ventral pallidus, ventral entopeduncular nucleus, and medial substantia nigra (Zahm and Heimer, 1990; Berendse et al., 1992b). The core has more striking similarities to dorsal striatum (neostriatum) with respect to input/output relations and would be expected to be closely associated with motor functions similar to the frontal cortexdorsal striatum system (Zahm and Heimer, 1990; Heimer et al., 1991).

The medial frontal cortex, which along with the NAS is considered to play an important role in reward mechanisms, is a candidate for generating anticipatory responses and it projects exclusively to the core area of the NAS (Phillipson and Griffiths, 1985; Brog et al., 1991). Rats self-stimulate and self-administer cocaine into the frontal cortex (Goeders and Smith, 1983; Robertson, 1989). In preliminary studies we have also observed anticipatory responses in rat frontal cortex during cocaine selfadministration. The frontal cortex has been thought to be critically involved in integrating sensory-motor planning (Niki and Watanabe, 1979; Fuster, 1989). Hence, our vicw is that thesc sustained anticipatory responses reflect activity from frontal cortex and other limbic structures that are related to planning and executing motor sequences leading to self-administration of drugs.

Hippocampal pyramidal cells exhibit "place cell" characteristics by firing in relation to position, direction, and velocity of the activation in the environment. The fact that the anticipatory responses were observed when rats performed a lever press in a spatially defined portion of the behavioral chamber is consistent with there being a hippocampal influence. The amygdala may be considered as another limbic area having an affect on the activity of NAS neurons. The basolateral amygdala has reciprocal connections with frontal cortex and also sends projections to the NAS (Ottersen, 1982; Kita and Kitai, 1990) that are subject to regulation by the VTA (Yim and Mogenson, 1983). It can be expected that the amygdala activates the N $\Lambda \mathrm{S}$ in correspondence to emotional aspects of the behavioral context (Nakano et al., 1987; Ono and Nishijo, 1992).

In this study, the randomly sampled population of neurons localized in the NAS was located predominantly in the larger core region ( $79 \%$ of neurons in core vs $21 \%$ in shell). All types of responses were represented in the core, which receives a substantial input from frontal cortex. The few responses observed in the shell may result from a spread of afferent fiber terminations. A more clear specification of which responses are delimited to core or shell, or to their chemically heterogeneous subregions (Zahm and Brog, 1992), will require larger recording sample sizes and increased resolution in histological reconstruction of recording sites.
Signals in nucleus accumbens as representations of motor planning

Since there are many anatomical similarities between the NAS and dorsal striatum, it is reasonable to consider the neuronal activity in both of these nuclei as being related to "motor planning," independent of a role in a reinforcement. Neuronal activity within the dorsal striatum is found to be linked to the presumed functions of the frontal motor or sensory cortical regions projecting to a particular area (Hikosaka et al., 1989ac; Alexander and Crutcher, 1990a,b; West et al., 1990). A principle emerging is that there is a progression in complexity of responses from specific limb-related sensory motor correlates found in the dorsolateral caudate putamen to more complex information expressed during delay period and cognitive neuronal activity in the head of caudate. Neural activity said to be consistent with a "representation of expectation" of sensory cues and intended movement related to motor planning has been described in the dorsal striatum (Apicella et al., 1992; Schultz and Romo, 1992a-c; Schultz et al., 1992). One might predict that activity in ventral striatum would parallel this trend and represent the highest levels of motor planning. Neural activity in the NAS may on one hand be related to "anticipation of reward," but the activity observed in this study may also simply reflect execution of a motor plan specific to obtaining a reward.

We take the term "representation," a key concept, to reflect the coding of information in the form of distributed activity within a neural circuit. We have found that even simple local feedback circuits modeled after the local inhibitory connections between medium spiny neurons in striatum can be found, when driven uniformly by depolarizing noise currents, to develop alternate on-off states of high or low activity analogous to shortterm or working memory (Kirillov et al., 1991, 1992, 1993; scc also Hopfield, 1984; Rumelhart and McClelland, 1986; Houk et al., 1993). Thus, such "expectation" responses may be intrinsic to both cortex or dorsal striatum.

Our hypothesis is that such sequences of spatial patterns of neuronal activity or "cortical representations" converge upon neurons in the dorsal and ventral striatum at different times and conditions to be used as parts of motor commands. Repeated propagation of information from the NAS may take place through ventral pallidus to the dorsomedial thalamic nucleus and back onto frontal cortex, perhaps involving different subpopulations of neurons. This operation within nested loops would enable the generation of sequential cortical signals used to drive the specific behavior. Wise and Hoffman (1992) have noted multiple ways that drugs can influence drug self-administration. A trigger system, a context determination, a pairing of associations, and a long-tcrm lcarning mechanism for reinforcing the operant task may all operate to control detailed aspects of self-administration behavior. These concepts may be reflected in the timing of the phasic signals generated at different stages of the lever press behavioral sequence (Fig. 16) as described in this study.

\section{References}

Akaike A, Sasa M, Takaori S (1984) Microiontophoretic studies of the dopaminergic inhibition from the ventral tegmental area to the nucleus accumbens neurons. J Pharmacol Exp Ther 229:859-864.

Alexander GE, Crutcher MD (1990a) Preparation for movement: neural representations of intended direction in three motor areas of the monkey. J Neurophysiol 64:133-150.

Alexander GE, Crutcher MD (1990b) Neural representations of the 
target (goal) of visually guided arm movements in three motor areas of the monkey. J Neurophysiol 64:164-178.

Apicella P, Ljungberg T, Scarnati E, Schultz W (1991) Responses to reward in monkey dorsal and ventral striatum. Exp Brain Res 85: 491-500.

Apicella P, Scarnati E, Ljungberg T, Schultz W (1992) Neuronal activity in monkey striatum related to the expectation of predictable environmental events. J Neurophysiol 68:945-959.

Berendse HW, Groenewegen HJ (1990) Organization of the thalamostriatal projections in the rat, with special emphasis on the ventral striatum. J Comp Neurol 299:187-228.

Berendse HW, Galis-de Graaf Y, Groenewegen HJ (1992a) Topographical organization and relationship with ventral striatal compartments of prefrontal corticostriatal projections in the rat. J Comp Neurol 316:314-347.

Berendse HW, Groenewegen HJ, Lohman AH (1992b) Compartmental distribution of ventral striatal neurons projecting to the mesencephalon in the rat. J Neurosci 12:2079-2103.

Blackburn JR, Phillips AG, Jakubovic A, Fibiger HC (1986) Dopamine turnover increases in anticipation of a meal. Appetite 7:243.

Britton DR, Curzon P, MacKenzie RG, Kebabian JW, Williams JEG, Kerkman D (1991) Evidence for involvement of both D1 and D2 receptors in maintaining cocaine self-administration. Pharmacol Biochem Behav 39:911-915.

Broderick PA (1991) Cocaine: on-line analysis of an accumbens amine neural basis for psychomotor behavior. Pharmacol Biochem Behav 40:959-968.

Brog JS, Deutch AY, Zahm DS (1991) Afferent projection to the nucleus accumbens core and shell in the rat. Soc Neurosci Abstr 17 : 454.

Chang J-Y, Sawyer SF, Lee R-S, Maddux BN, Woodward DJ (1990) Activity of neurons in nucleus accumbens during cocaine self-administration in freely moving rats. Soc Neurosci Abstr 16:252.

Chang J-Y, Sawyer SF, Lee R-S, Woodward DJ (1991) Correlation between nucleus accumbens neuronal activity and cocaine self-administration behavior in rats. Soc Neurosci Abstr 17:679.

Christie MJ, Summers R J, Stephenson JA, Cook CJ, Reart PM (1987) Excitatory amino acid projections to the nucleus accumbens septi in the rat: a retrograde transport study utilizing $\mathrm{D}\left[{ }^{3} \mathrm{H}\right]$ aspartate and $\left[{ }^{3} \mathrm{H}\right] \mathrm{GABA}$. Neuroscience 22:425-439.

de Wit H, Wise RA (1977) Blockade of cocaine reinforcement in rats with the dopamine receptor blocker pimozide, but not with the noradrenergic blockers phentolamine or phenoxybenzamine. Can J Psychol 31:195-203.

DeFrance JF, Marchand JF, Sikes RW, Chronister RB, Hubbard JI (1985) Characterization of fimbria input to nucleus accumbens. J Neurophysiol 54:1553-1567.

Domesick VB (1981) Further observation on the anatomy of nucleus accumbens and caudatoputamen in the rat: similarities and contrasts. In: Neurobiology of the nucleus accumbens (Chronister RB, DeFrance JF, eds), pp 7-39. Brunswick, ME: Haer Institute for Electrophysiological Research.

Einhorn LC, Johansen PA, White FJ (1988) Electrophysiological effects of cocaine in the mesoaccumbens dopamine system: studies in the ventral tegmental area. J Neurosci 8:100-112.

Ettenberg A, Pettit HO, Bloom FE, Koob GF (1982) Heroin and cocaine intravenous self-administration in rats: mediation by separate neural system. Psychopharmacology 78:204-209.

Fukuzako H, Nagatomo I, Nomaguchi M, Takenouchi K, Matsumoto $\mathrm{K}$ (1988) Alterations of accumbens neuronal activity in freely moving rats following methamphetamine. Jpn J Psychiatry Neurol 42: 331-335.

Fuster JM (1989) The prefrontal cortex. Anatomy, physiology, and neuropsychology of the frontal lobe. New York: Raven.

Goeders NE, Smith IE (1983) Cortical dopaminergic involvement in cocaine reinforcement. Science 221:773-775.

Green JD (1958) A simple microelectrode for recording from the central nervous system. Nature 182:962.

Groenewegen HJ, Russchen FT (1984) Organization of the efferent projections of the nucleus accumbens to pallidal, hypothalamic, and mesencephalic structures: a tracing and immunohistochemical study in the cat. J Comp Neurol 223:347-367.

Groenewegen HJ, Room P, Witter MP, Lohman AHM (1982) Cortical afferents of the nucleus accumbens in the cat, studied with anterograde and retrograde transport techniques. Neuroscience 7:977-995.
Groenewegen HJ, Vermeulen-Van Der Zee E, Te Kortschot A, Witter MP (1987) Organization of the projections from the subiculum to the ventral striatum in the rat. A study using anterograde transport of Phaseolus vulgaris leucoagglutinin. Neuroscience 23:103-120.

Heffner TG, Hartman JA, Seiden LS (1980) Feeding increases dopamine metabolism in the rat brain. Seience 208:1168-1170.

Heikkila RE, Orlansky H, Cohen G (1975) Studies on the distinction between uptake inhibition and release of $\left[{ }^{3} \mathrm{H}\right]$ dopamine in rat brain tissue slices. Biochem Pharmacol 24:847-852.

Heimer L, Wilson RD (1975) The subcortical projections of the allocortex: similarities in the neural association of the hippocampus, the piriform cortex, and the neocortex. In: Golgi Centennial symposium, Perspectives in neurobiology (Santini M, ed), pp 177-193. New York: Raven.

Heimer L, Zahm DS, Churchill L, Kalivas PW, Wohltmann C (1991) Specificity in the projection patterns of accumbal core and shell in the rat. Neuroscience 41:89-125.

Hikosaka O, Sakamoto M, Usui S (1989a) Functional properties of monkey caudate neurons. I. Activities related to saccadic eye movements. J Neurophysiol 61:780-798.

Hikosaka O, Sakamoto M, Usui S (1989b) Functional properties of monkey caudate neurons. II. Visual and auditory responses. J Neurophysiol $61: 799-813$

Hikosaka O, Sakamoto M, Usui S (1989c) Functional properties of monkey caudate neurons. III. Activities related to expectation of target and reward. J Neurophysiol 61:814-832.

Hopfield JJ (1984) Neurons with graded responses have collective computational properties like that of two state neurons. Proc Natl Acad Sci USA 81:3088-3092

Houk JC, Keifer J, Barto AG (1993) Distributed motor commands in the limb premotor network. Trends Neurosci 16:27-33.

Hurd YL, Weiss F, Koob GF, And N-E, Ungerstedt U (1989) Cocaine reinforcement and extracellular dopamine overflow in rat nucleus accumbens: an in vivo microdialysis study. Brain Res 498:199-203.

Kelley AE, Domesick VB (1982) The distribution of the projection from the hippocampal formation to the nucleus accumbens in the rat: an anterograde- and retrograde-horseradish peroxidase study. Neuroscience 7:2321-2335.

Kelley AE, Domesick VB, Nauta WJH (1982) The amygdalostriatal projection in the rat-an anatomical study by anterograde and retrograde tracing methods. Neuroscience 7:615-630.

Kennedy LT, Hanbauer I (1983) Sodium-sensitive cocaine binding to rat striatal membrane: possible relationship to dopamine uptake sites. J Neurochem 41:172-178.

Kirillov AB, Myre CD, Woodward DJ (1991) Bistable neurons and memory patterns in the inhibitory-feedback model inspired by neostriatum. Soc Neurosci Abstr 17:124.

Kirillov AB, Myre CD, Woodward DJ (1992) Working memory in small inhibitory-feedback neural networks. Soc Neurosci Abstr 18: 318

Kirillov AB, Myre CD, Woodward D (1993) Bistability, switches and working memory in a two-neuron inhibitory-feedback model. Biol Cybern 68:441-449.

Kita H, Kitai ST (1990) Amygdaloid projects to the frontal cortex and the striatum in the rat. J Comp Neurol 298:40-49.

Koob GF, Bloom FE (1988) Cellular and molecular mechanisms of drug dependence. Science 242:715-723.

Koob GF, Le HT, Creese I (1987) The D dopamine receptor antagonist SCH 23390 increases cocaine self-administration in the rat. Neurosci Lett 79:315-320.

Kurumiya S, Nakajima S (1988) Dopamine $\mathrm{D}_{1}$ receptors in the nucleus accumbens: involvement in the reinforcing effect of tegmental stimulation. Brain Res 448:1-6.

Le Moal M, Simon H (1991) Mesocorticolimbic dopaminergic networks: functional and regulatory roles. Physiol Rev 71:155-234.

Maldonado R, Robledo P, Chover AJ, Koob GF (1991) The effects on cocaine self-administration of different dopamine antagonists injected into the nucleus accumbens. Soc Neurosci Abstr 17:683.

McDonald AJ (1991) Topographical organization of amygdaloid projections to the caudatoputamen, nucleus accumbens, and related striatal-like areas of the rat brain. Neuroscience 44:15-33.

Mogenson GJ (1987) Limbic-motor integration. Prog Psychobiol Physiol Psychol 12:117-170.

Mogenson GJ, Takigawa M, Robertson A, Wu M (1979) Self-stimulation of the nucleus accumbens and ventral tegmental area of Tsai 
attenuated by microinjections of spiroperidol into the nucleus accumbens. Brain Res 171:247-259.

Mogenson GJ, Swanson LW, Wu M (1983) Neural projections from nucleus accumbens to globus pallidus, substantia innominata, and lateral preoptic-lateral hypothalamic area: an anatomical and electrophysiological investigation in the rat. J Neurosci 3:189-202.

Nakano $Y$, Lénárd L, Oomura $T$, Nishino $H$, Aou $S$, Yamamoto $T$ (1987) Functional involvement of catecholamines in reward-related neuronal activity of the monkey amygdala. J Neurophysiol 57:7291.

Nauta WJH, Smith GP, Faull RLM, Domesick VB (1978) Efferent connections and nigral afferents of the nucleus accumbens septi in the rat. Neuroscience 3:385-401.

Nayak PK, Misra AL, Mulé SJ (1976) Physiological disposition and biotransformation of $\left.{ }^{3} \mathrm{II}\right]$ cocaine in acutely and chronically treated rats. J Pharmacol Exp Ther 196:556-569.

Niki H, Watanabe M (1979) Prefrontal and cingulate unit activity during timing behavior in the monkey. Brain Res 171:213-224.

Oades RD, Halliday GM (1987) Ventral tegmental (A10) system: neurobiology. 1. Anatomy and connectivity. Brain Res Rev 12:117165.

Ono T, Nishijo H (1992) Neurophysiological basis of the Klüver-Bucy syndrome: responses of monkey amygdaloid neurons to biologically significant objects. In: The amygdala (Aggleton JP, ed), pp 167-190. New York: Wiley-Liss.

Ottersen OP (1982) Connections of the amygdala of the rat. IV: Cortioamygdaloid and intraamygdaloid connections as studied with axonal transport of horseradish peroxidase. J Comp Neurol 205:30-48.

Paxinos G, Watson C (1986) The rat brain in stereotaxic coordinates. San Diego: Academic.

Pennartz CMA, Boeijinga PH, Kitai ST, Lopes da Silva FH (1991) Contribution of NMDA receptors to postsynaptic potentials and pairedpulse facilitation in identified neurons of the rat nucleus accumbens in vitro. Exp Brain Res 86:190-198.

Peoples LL, West MO (1990) Effects of intravenous cocaine on single unit activity in the nucleus accumbens of freely-moving rats. Soc Neurosci Abstr 16:252.

Pettit HO, Justice JB Jr (1989) Dopamine in the nucleus accumbens during cocaine self-administration as studied by in vivo microdialysis. Pharmacol Biochem Behav 34:899-904.

Pettit HO, Justice JB Jr (1991) Effect of dose on cocaine self-administration behavior and dopamine levels in the nucleus accumbens. Brain Res 539:94-102.

Pettit HO, Ettenberg A, Bloom FE, Koob GF (1984) Destruction of dopamine in the nucleus accumbens selectively attenuates cocaine but not heroin self-administration in rats. Psychopharmacology 84: 167-173.

Phillips AG, Broekkamp CL, Fibiger HC (1983) Strategies for studying the neurochemical substrates of drug reinforcement in rodents. Prog Neuropsychopharmacol Biol Psychiat 7:585-590.

Phillipson OT, Griffiths AC (1985) The topographic order of inputs to nucleus accumbens in the rat. Neuroscience 16:275-296.

Pickens R, Thompson T (1968) Cocaine-reinforced behavior in rats: effects of reinforcement magnitude and fixed-ratio size. J Pharmacol Exp Ther 161:122-129.

Pulvirenti L, Swerdlow NR, Hubner CB, Koob GF (1991) The role of limbic-accumbens-pallidal circuitry in the activating and reinforcing properties of psychostimulant drugs. In: The mesolimbic dopamine system: from motivation to action (Willner P, Scheel-Kruger J, eds), pp 131-140. New York: Wiley.

Ritz MC, Lamb RJ, Goldberg SR, Kuhar MJ (1987) Cocaine receptors on dopamine transporters are related to self-administration of cocaine. Science 237:1219-1223.

Roberts DCS, Corcoran ME, Fibiger HC (1977) On the role of ascending catecholaminergic systems in intravenous self-administration of cocaine. Pharmacol Biochem Behav 6:615-620.

Roberts DCS, Koob GF, Klonoff P, Fibiger HC (1980) Extinction and recovery of cocaine self-administration following 6-hydroxydopamine lesions of the nucleus accumbens. Pharmacol Biochem Behav 12: 781-787.

Robertson A (1989) Multiple reward system and the prefrontal cortex. Neurosci Biobehav Rev 13:163-170.

Robertson GS, Pfaus JG, Atkinson LJ, Matsumura $H$, Phillips $A G$, Fibiger HC (1991) Sexual behavior increases c-fos expression in the forebrain of the male rat. Brain Res 564:352-357.
Robinson TG, Beart PM (1988) Excitant amino acid projections from rat amygdala and thalamus to nucleus accumbens. Brain Res Bull $467-471$.

Rolls ET (1984) Responses of neurons in different regions of the striatum of the behaving monkey. In: The basal ganglia-structure and function (McKenzie JS, Kemm RE, Wilcock LN, eds), pp 467-493. New York: Plenum.

Rumelhart DE, McClelland JL (1986) Parallel distributed processing: explorations in the microstructures of cognition, Vol 1. Cambridge, MA: MIT Press.

Schultz W, Romo R (1992a) Role of primate basal ganglia and frontal cortex in the internal generation of movements. I. Preparatory activity in the anterior striatum. Exp Brain Res 91:363-384.

Schultz W, Romo R (1992b) Role of primate basal ganglia and frontal cortex in the internal generation of movements. II. Movement-related activity in the anterior striatum. Exp Brain Res 91:385-395.

Schultz W, Romo R (1992c) Role of primate basal ganglia and frontal cortex in the internal generation of movements. III. Neuronal activity in the supplementary motor area. Exp Brain Res 91:396-407.

Schultz W, Apicella P, Scarnati E, Ljungberg T (1992) Neuronal activity in monkey ventral striatum related to the expectation of reward. J Neurosci 12:4595-4610.

Stellar JR, Corbett D (1989) Regional neuroleptic microinjections indicate a role for nucleus accumbens in lateral hypothalamic selfstimulation reward. Brain Res 477:126-143.

Su HS, Bentivoglio M (1990) Thalamic midline cell populations projecting to the nucleus accumbens, amygdala, and hippocampus in the rat. J Comp Neurol 297:582-593.

Swanson LW (1982) The projections of the ventral tegmental area and adjacent regions: a combined fluorescent retrograde tracer and immunofluorescence study in the rat. Brain Res Bull 9:321-353.

Uchimura N, Haggish H, Nishi S (1989) Membrane properties and synaptic responses of the guinea pig nucleus accumbens neurons in vitro. J Neurophysiol 61:769-779.

Unemoto H, Sasa M, Takaori S (1985) Inhibition from locus coeruleus of nucleus accumbens neurons activated by hippocampal stimulation. Brain Res 338:376-379.

West MO, Carelli RM, Pomerantz M, Cohen SM, Gardner JP, Chapin JK, Woodward DJ (1990) A region in the dorsolateral striatum of the rat exhibiting single-unit correlations with specific locomotor limb movements. J Neurophysiol 64:1233-1246.

White FJ (1987) D-1 dopamine receptor stimulation enables the inhibition of nucleus accumbens neurons by a D-2 receptor agonist. Eur J Pharmacol 135:101-105.

White FJ, Wang RY (1986) Electrophysiological evidence for the existence of both D-1 and D-2 dopamine receptors in the rat nucleus accumbens. J Neurosci 6:274-280.

White FJ, Wachtel SR, Johansen PA, Einhorn LC (1987) Electrophysiological studies of the rat mesoaccumbens dopamine system: focus on dopamine receptor subtypes, interactions, and effects of cocaine. In: Neurophysiology of dopaminergic systems - current status and clinical perspectives (Chiodo LS, Freeman AS, eds), pp 317-365. Lakeshore.

Wise RA (1989) The hrain and reward. In: The neuropharmacological basis of reward (Liebman JM, Cooper SJ, eds), pp 377-424. Oxford: Clarendon.

Wise RA, Hoffman DC (1992) Localization of drug reward mechanisms by intracranial injections. Synapse 10:247-263.

Wise RA, Yokel RA, Hansson P, Geiber GJ (1977) Concurrent intracranial self stimulation and amphetamine self administration in rats. Pharmacol Biochem Behav 7:459-461.

Wolske M, Rompre P-P, Wise RA, West MO (1993) Activation of single neurons in the rat nucleus accumbens during self-stimulation of ventral tegmental area. J Neurosci 13:1-12.

Woolverton WL (1986) Effects of a $D_{1}$ and a $D_{2}$ dopamine antagonist on the self-administration of cocaine and piribedil by rhesus monkeys. Pharmacol Biochem Behav 24:531-535.

Yang CR, Mogenson GJ (1984) Electrophysiological responses of neurones in the nucleus accumbens to hippocampal stimulation and the attenuation of the excitatory responses by the mesolimbic dopaminergic system. Brain Res 324:69-84.

Yang CR, Mogenson GJ (1987) Hippocampal signal transmission to the pedunculopontine nucleus and its regulation by dopamine $D_{2}$ receptors in the nucleus accumbens: an electrophysiological and behavioural study. Neuroscience 23:1041-1055. 
Yang CR, Mogenson GJ (1989) Ventral pallidal neuronal responses to dopamine receptor stimulation in the nucleus accumbens. Brain Res 489:237-246.

Yim CY, Mogenson GJ (1983) Response of ventral pallidal neurons to amygdala stimulation and its modulation by dopamine projection to nucleus accumbens. J Neurophysiol 50:148-161.

Yim CY, Mogenson GJ (1988) Neuromodulatory action of dopamine in the nucleus accumbens: an in vivo intracellular study. Neuroscience $26: 403-415$.

Yokel RA, Wise RA (1975) Increased lever pressing for amphetamine after pimozide in rats: implications for a dopamine theory of reward. Science 187:547-549.

Zaborszky L, Alheid GF, Beinfeld MC, Eiden LE, Heimer L, Palkovits
M (1985) Cholecystokinin innervation of the ventral striatum: a morphological and radioimmunological study. Neuroscience 14:427453.

Zahm DS, Brog JS (1992) On the significance of subterritories in the "accumbens" part of the rat ventral striatum. Neuroscience 50:751767

Zahm DS, Heimer L (1990) Two transpallidal pathways originating in the rat nucleus accumbens. J Comp Neurol 302:437-446.

Zar JH (1984) Biostatistical analysis. Englewood Cliffs, NJ: Prentice Hall.

Zito KA, Vickers G, Roberts DCS (1985) Disruption of cocaine and heroin self-administration following kainic acid lesions of the nucleus accumbens. Pharmacol Biochem Behav 23:1029-1036. 